\title{
Trade Liberalization and Child Mortality: A Synthetic Control Method*
}

\author{
Alessandro Olper ${ }^{\mathrm{a}, \mathrm{b}}$ \\ alessandro.olper@unimi.it \\ Daniele Curzi ${ }^{\text {a }}$ \\ daniele.curzi@unimi.it \\ and Johan Swinnen ${ }^{\mathrm{b}}$ \\ jo.swinnen@kuleuven.be
}

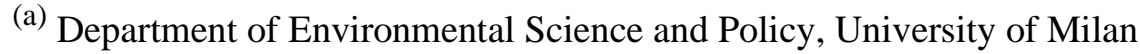

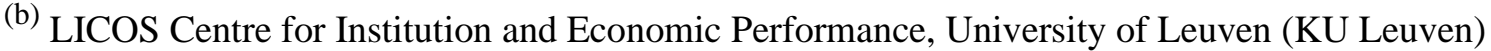

\begin{abstract}
We study the effect of trade liberalization on child mortality using data from emerging and developing countries over the 1960-2010 period. To capture possible heterogeneity of effects, we use the Synthetic Control Method (SCM) for comparative case studies. The SCM allows to compare the trajectory of post-reform health outcomes of treated countries (those which experienced trade liberalization) with the trajectory of a combination of similar but untreated countries. On average, trade liberalization significantly reduced child mortality. The average reduction is around 9\% ten years after the liberalization. But there is significant heterogeneity in the impact. For the cases for which the SCM could provide a reliable counterfactual, trade liberalization significantly reduced child mortality in approximately half the cases. In most other cases there was no significant effect. In the majority of the significant cases, the reduction in child mortality was more than $20 \%$. On average, trade liberalization reduced child mortality more (a) in democracies compared to autocracies, (b) when incomes were higher and (c) when it reduced taxation of farmers.
\end{abstract}

Keywords: Trade liberalization, Child Mortality, Synthetic Control Method.

JEL Classification: Q18, O24, O57, I15, F13, F14.

${ }^{*}$ Corresponding author: alessandro.olper@unimi.it.

The research leading to these results has received funding from the European Union's Seventh Framework programme FP7 under Grant Agreement n²90693 FOODSECURE - Exploring the Future of Global Food and Nutrition Security. The views expressed are the sole responsibility of the authors and do not necessarily reflect the views of the European Commission. 


\section{Introduction}

The impact of globalization and trade liberalization on welfare and poverty remains controversial (Harrison, 2006; Ravallion, 2003). While several economic studies show that open trade enhances economic growth (e.g. Dollar, 1992; Sachs and Warner, 1995; Giavazzi and Tabellini, 2008; Wacziarg and Welch, 2008; Bilmeier and Nannicini, 2013), the impact on poverty and inequality is much less clear (e.g. Goldberg and Pavcnik, 2007; Topalova, 2010; Anukriti and Kumler, 2014). In an elaborate review of the evidence, Winters et al. (2004) conclude that "there can be no simple general conclusions about the relationship between trade liberalization and poverty". In a recent update, Winters and Martuscelli (2014) argue that this conclusion still holds. ${ }^{1}$

In this paper we study the impact of trade liberalization on health, and more specifically child mortality. While children's health is an important indicator of welfare and poverty (Deaton, 2003), it is also an important end in its own right (Sen, 1999). Moreover child health is also itself important for economic growth and development (Levine and Rothman, 2006).

There is an extensive literature addressing the issue and the mechanisms through which trade may affect health, and in particular child mortality (see Blouin et al. 2009 for a survey). These include the impact on economic growth, poverty and inequality (Pritchett and Summers 1996; Deaton, 2003), public health expenditures (Kumar et al. 2013; Filmer and Pritchett, 1999), knowledge spillovers (Deaton, 2004; Owen and Wu, 2007), dietary changes (Cornia et al. 2008; Chege et al. 2015; Oberländer et al. 2016), food prices (Headey, 2014; Fledderjohann et al. 2016), fertility and the labour market (Anukriti and

\footnotetext{
${ }^{1}$ See also Goldberg and Pavcnik $(2004 ; 2007)$ for extensive reviews on the poverty and distributional effects of trade liberalization in developing countries; as well as Wade (2004) and a special issue of this Journal edited by Nissanke and Thorbecke (2006).
} 
Kumler 2014). Not only are there many ways that trade may affect people's health, the impact may be both positive and negative.

Some studies have tried to quantitatively assess the impact of trade (or globalization more generally) on health using cross-country data (e.g. Martens et al. (2010) and Mukerjee and Kreckhaus (2011)). However, while they find a correlation, most studies do not convincingly deal with endogeneity bias, due to omitting variables and/or simultaneity between globalization indicators and the health variables, to identify causal effects.

Two studies (Levine and Rothman (2006) and Owen and Wu (2010)) are more careful in their econometric identification strategy and dealing with causality issues. Levine and Rothman (2006) use a cross-country analysis to measure the (long-run) effect of trade on life expectancy and child mortality. Because trade can be endogenous to income and health, they follow Frankel and Romer's (1999) approach by exploiting the exogenous component of trade predicted from a gravity model. They find that trade significantly improves health outcomes, although the effect tends to be weaker and often insignificant when they control for countries' income levels and some other covariates. The authors conclude that one of the main channels through which trade openness improves health is through enhanced incomes. Owen and $\mathrm{Wu}$ (2007) use panel data econometrics. Controlling for income and other observed and unobserved determinants of health through fixed effects, they find that trade openness improves life expectancy and child mortality in a panel of more than 200 developed and developing countries. They also find evidence suggesting that some of the positive correlations between trade and health can be attributed to knowledge spillovers - an hypothesis previously advanced by Deaton (2004). However, also in their analysis the impact is not always robust. For example, when the authors work with the sub-sample of only developing countries, the trade effect on health is weaker, and not significant when child mortality is considered. 
Given the fact that trade can affect health, and in particular child mortality, through different channels, and that the impact of trade liberalization can be different under different economic and institutional conditions, the average effect as measured by previous cross-country studies may hide important heterogeneity among countries and regions (Bardhan, 2006; Nissanke and Thorbecke, 2006; Ravallion and Chen, 2007; Winters et al. 2004).

To explicitly capture this potential heterogeneity we use a different methodology than previous studies, namely the Synthetic Control Method (SCM) recently developed by Abadie and Gardeazabal (2003) and by Abadie et al. (2010). We follow the approach of Billmeier and Nannicini (2013) and Cavallo et al. (2013) who applied the SCM to study the relationship between trade liberalization, economic growth and natural catastrophes, respectively. The SCM allows choosing the best comparison units in comparative case studies. Using this approach, we compare the post-reform child mortality of countries that experienced trade liberalization - treated countries - with child mortality of a combination of similar, but untreated countries.

The SCM methodology allows flexibility and transparency in the selection of the counterfactual, and thus improves the comparability between treated and untreated units. Importantly, the SCM also accounts for endogeneity bias due to omitted variables by accounting for the presence of time-varying unobservable confounders. Moreover, it allows separating short-run versus long-run effects, an issue not formally addressed by previous studies but of particular relevance when the focus of the analysis is the effect of trade reforms (Billmeier and Nannicini, 2013).

We use data from 41 cases of trade liberalizations in developing and emerging countries which occurred during the $1960-2010$ period. Not all cases satisfy the SCM methodological properties. Among the cases that satisfy the SCM criteria, we find 
significant heterogeneity in the effects. On average, trade liberalization significantly reduced child mortality, but in several cases there was no significant impact, and in a few cases child mortality increased after trade liberalization. In the second part of the paper we discuss potential factors (including interactions of trade liberalization with taxation structures, the level of development, the spread of diseases, etc.) which may explain these heterogeneous effects.

The remainder of the paper is organized as follows. In the next section the methodology - the synthetic control approach - will be presented and discussed. Section 3 presents the data on trade policy reforms, child mortality and other covariates used in the empirical exercise. In Section 4 the main results will be presented and discussed. Section 5 presents robustness checks and some extensions, while in Section 6 we further investigate potential mechanisms. Section 7 concludes.

\section{Methodology}

The empirical identification of the causal effect of trade policies on health outcomes is difficult because trade policies tend to be correlated with many other social, political and economic factors. Moreover, the effect of trade policies on inequality and poverty tends to be country-, time- and case-specific (see Goldberg and Pavcnik, 2004; 2007).

Previous quantitative studies do not fully account for all these issues simultaneously. The instrumental variable approach of Levine and Rothman (2006), relies on the assumption that the estimated trade share from gravity model is not correlated with other factors, such as institutions or growth, that by themselves could affect child mortality (see Nunn and Trefler, 2014). The panel fixed effects approach proposed by Owen and $\mathrm{Wu}$ (2007) assumed that in absence of trade reforms, health outcomes for the treated and control groups would have followed parallel trajectories over time, an 
assumption often violated and sensitive to the fixed effects specification (Bertrand et al. 2004; Ryan et al. 2015). ${ }^{2}$ In addition, both these approaches do not provide insights on the potential heterogeneity of the trade reforms effects on poverty and inequality.

To overcome the identification problem we use the synthetic control method (SCM) proposed by Abadie and Gardeazabal (2003) and Abadie et al. (2010). The SCM is an approach for programme evaluation, developed in the context of comparative case studies, that relaxes the parallel trends assumption of the difference-in-difference method. ${ }^{3}$ The SCM, besides accounting for time varying unobserved effects, is particularly suitable for those contexts where the effect of the policy under investigation is supposed to be heterogeneous across the investigated units. Moreover, as the SCM offers a dynamic estimate of the average effects, its results add additional insights on the dynamic effect of trade policy reforms on health outcomes, as some of the effects may require time to emerge (Billmeier and Nannicini, 2013). Finally, the SCM estimator is both externally and internally valid, as it combines properties of large cross-country studies, which often lack internal validity, and of single country-case studies, that often cannot be generalized.

In what follows we summarize the SCM approach following Abadie et al. (2010) and Billmeier and Nannicini (2013) who studied the relation between trade liberalization and growth. We also discuss the problem of aggregation of the units of investigation based on Cavallo et al. (2013).

\footnotetext{
${ }^{2}$ In fact, Owen and $\mathrm{Wu}$ pooled together developed and developing countries in the same fixed effects regression. In so doing, as an effect of the Preston curve (see Preston, 1975) in the relation between health and income, the probability that the parallel assumption inherent in fixed effects model is violated, appears high in this context.

${ }^{3}$ See Ryan et al. (2015) for an in depth discussion about the plausibility of the parallel assumption of the difference-in-difference (DiD) estimator, and Kreif et al. (2016) for a comparison of DiD with the synthetic control method in the context of health policy.
} 


\subsection{The Synthetic Control Method}

Consider a panel of $I_{\mathrm{C}}+1$ countries over $T$ periods, where country $I$ changes its trade policy at time $T_{0}<T$, while all the other countries of $I_{\mathrm{C}}$ remain closed to international trade, thus representing a sample of potential control or donor pool. The treatment effect for country $i$ at time $t$ can be defined as follows:

$$
\tau_{i t}=Y_{i t}(1)-Y_{i t}(0)=Y_{i t}-Y_{i t}(0)
$$

where $Y_{i t}(T)$ represents the potential outcome associated with $T \in\{0,1\}$, that in our application refers to the level of under five mortality rate in an economy closed (0) or open (1) to international trade, respectively. The statistic of interest is the vector of dynamic treatment effects $\left(\tau_{i, T_{0}+1}, \ldots, \tau_{i, T}\right)$. As is well known from the program evaluation literature, in any period $t>T_{0}$ the estimation of the treatment effect is complicated by the lack of the counterfactual outcome, $Y_{i t}(0)$. To circumvent this problem, the SCM identifies the above treatment effects under the following general model for potential outcomes (Abadie et al. 2010):

$$
Y_{j t}(0)=\delta_{t}+X_{j} \theta_{t}+\lambda_{t} \mu_{j}+\varepsilon_{j t}
$$

where $\delta_{t}$ is an unknown common term with constant factor loadings across units; $X_{j}$ is a vector of relevant observed covariates (not affected by the intervention) and $\theta_{t}$ the related vector of parameters; $\mu_{j}$ is a country specific unobservable, with $\lambda_{t}$ representing the unknown common factor; ${ }^{4}$ finally, $\varepsilon_{j t}$ are transitory shocks with zero mean. As explained later on, the variables that we include in the vector $X_{j}$ (real per capita GDP, population growth, fraction of rural population, frequency of wars and conflicts, female primary education, and child mortality) refer to the pre-treatment period. Hence, we are assuming

\footnotetext{
${ }^{4}$ Note that standard difference-in-differences approach set $\lambda_{t}$ to be constant across time. Differently, the SCM allows the impact of unobservable country heterogeneity to vary over time.
} 
that they are exogenous, and thus not affected by the treatment (trade liberalization) ${ }^{5}$ and that there are no "anticipation" effects (see Abadie, 2013).

Next, define $W=\left(w_{1}, \ldots, w_{I_{C}}\right)^{\prime}$ as a generic $\left(I_{C} \times 1\right)$ vector of weights such that $w_{j} \geq 0$ and $\sum w_{j}=1$. Every value of $W$ represents a possible counterfactual for country i. Moreover, define $\bar{Y}_{j}^{k}=\sum_{s=1}^{T_{0}} k_{s} Y_{j s}$ as a linear combination of pre-treatment outcomes. Abadie et al. (2010) showed that, as long as one can choose $W^{*}$ such that

$$
\sum_{J=1}^{I_{C}} w_{j}^{*} \bar{Y}_{j}^{k}=\bar{Y}_{i}^{k} \quad \text { and } \quad \sum_{J=1}^{I_{C}} w_{j}^{*} X_{j}=X_{i}
$$

then

$$
\hat{\tau}_{i t}=Y_{i t}-\sum_{J=1}^{I_{C}} w_{j}^{*} Y_{j t}
$$

is an unbiased estimator of the average treatment effect, $\tau_{i t}$.

Note that condition (3) can hold exactly only if $\left(\bar{Y}_{j}^{k}, X_{j}\right)$ belongs to the convex hull of $\left[\left(\bar{Y}_{1}^{k}, X_{j}\right), \ldots,\left(\bar{Y}_{I_{C}}^{k}, X_{I_{C}}\right)\right]$. However, in practice, the synthetic control $W^{*}$ is selected so that condition (3) holds approximately. This is obtained by minimizing the distance between the vector of pre-treatment characteristics of the treated country and the vector of the pre-treatment characteristics of the potential synthetic control, with respect to $W^{*}$, according to a specific metric. ${ }^{6}$ Then, any deviation from condition (3) imposed by this procedure can be evaluated in the data, and represents a part of the SCM output. ${ }^{7}$

\footnotetext{
${ }^{5}$ This assumption may appear strong, given that a large literature shows that trade liberalization can affect GDP, education etc.. However, all these covariates (except for child mortality) enter in the SCM algorithm as average values over the 10 years before trade liberalization occurs. Thus the probability that they are affected by the reforms, is by construction, very low.

${ }^{6}$ Abadie et al. (2010) choose $W^{*}$ as the value of $W$ that minimizes: $\sum_{m=1}^{k} v_{m}\left(X_{1 m}-X_{0 m} W\right)^{2}$, where $v_{m}$ is a weight that reflects the relative importance that we assign to the $m$-th variable when we measure the discrepancy between $X_{1}$ and $X_{0} W$. Typically, these weights are selected in accordance to the covariates' predictive power on the outcome. We followed the same approach.

${ }^{7}$ In particularly, one of the key outcomes of the SCM procedure is the estimate of the root mean square predicted error (RMSPE) between the treated and the synthetic control, measured in the pre-treatment period.
} 
The SCM has three key advantages in comparison with the DiD and other estimators normally used in the program evaluation literature. First, it is more transparent, as the weights $W^{*}$ clearly identify the countries that are used to estimate the counterfactual. Second, it is more flexible because the set of $I_{C}$ potential controls can be restricted to make the underlying country comparisons more appropriate. Third, it is based on identification assumptions that are weaker, as it allows for the effect of unobservable confounding factors to be time variant. Yet, identification is still based on the assumption that the attribution of a given treatment to one country does not affect the other countries, and/or that there are not spillover effects (stable unit treatment value assumption (SUTVA)). ${ }^{8}$

The SCM methodology has two main drawbacks. First, it does not distinguish between direct and indirect causal effects, a standard weakness of program evaluation methods (Cavallo et al. 2013). One could argue that in our specific analysis this is somewhat less a problem since the effects of trade liberalization are mostly indirect (Blouin et al. (2009) - see also introduction). Second, the small number of observations often involved in such case studies translates into the impossibility to use standard inferential techniques. Following Abadie et al. (2010) we try to address this problem by making use of placebo tests. These tests compare the magnitude of the estimated effect on the treated country with the size of those obtained by assigning the treatment randomly to any (untreated) country of the donor pool.

\subsection{Measuring Average Effects}

\footnotetext{
${ }^{8}$ Working with macro data and trade reforms, the probability that the treatment assignment to one country may have - partial or general equilibrium - effects on the others could not, a priory, be ruled out. However, as we will argue in the results section, in our specific context this problem does not appear particularly severe.
} 
In previous SCM applications the analysis of the results have been largely conducted at the level of (each) single unit of investigation, e.g. at the country level. However, when the analysis covers many countries, as in the present study, it may be interesting to measure the average treatment effects for specific groups of countries. To do this, we follow the approach by Cavallo et al. (2013). Denote by $\left(\hat{\tau}_{1, T 0+1}, \ldots, \hat{\tau}_{1, T}\right)$ a specific estimation of the trade liberalization effects on child mortality of the country of interest 1 . The average trade liberalization effects across $G$ countries of interest can then be computed as:

$$
\bar{\tau}=\left(\bar{\tau}_{T 0+1}, \ldots, \bar{\tau}_{T}\right)=G^{-1} \sum_{g=1}^{G}\left(\hat{\tau}_{g, T 0+1}, \ldots, \hat{\tau}_{g, T}\right) .9
$$

To estimate whether this (dynamic) average treatment effect is statistically significant, Cavallo et al. (2013) proposed an approach that allows consistent inference measurement regardless of the number of available controls or pre-treatment periods, although the precision of inference clearly increases with their number. The underlying logic of this methodology is to first apply the SCM algorithm to every potential control in the donor pool to evaluate whether the estimated effect of the treated country outperforms the ones of the fake experiments. ${ }^{10}$

Furthermore, because we are interested in valid inferences on the $\bar{\tau}$ average effect, we need to construct the distribution of the average placebo effects to compute the year $t$ average specific $p$-value. Following Cavallo et al. (2013), we first compute all the

\footnotetext{
${ }^{9}$ Note also that, because the size of the country specific effect will depend on the level of the child mortality rate, one needs to normalize the estimates before aggregating the individual country effects This is done by setting the child mortality of the treated country equal to 1 in the year of trade reform, $T_{0}$.

${ }^{10}$ For example, if one wants to measure inference for the trade liberalization effect on child mortality for each of the ten post-reform years, it is possible to compute the year-specific significance level, namely the $p$-value, for the estimated trade reform effect as follows: $p$-value $t=\operatorname{Pr}\left(\hat{\tau}_{1, t}^{P L}<\hat{\tau}_{1, t}\right)=\frac{\sum_{j=2}^{J+1} I\left(\hat{\tau}_{1, t}^{P L_{j}}<\hat{\tau}_{1, t}\right)}{\# \text { of controls }}$, where $\hat{\tau}_{1, t}^{P L}$ is the year specific effect of trade reform when control country $j$ is assigned a placebo reform at the same time as the treated country 1 and is calculated using the same algorithm outlined for $\hat{\tau}_{1, t}$. The operation is performed for each country $j$ of the donor pool to build the distribution of the fake experiments so as to evaluate how the estimate $\hat{\tau}_{1, t}$ is positioned in that distribution.
} 
placebo effects for the treated countries, as summarized in footnote 10. As we are interested in computing the $p$-value of the average effect, we then consider at each year of the post-treatment period, all the possible average placebo effects for any possible aggregation of placebos, $G$. The number of possible placebo averages is computed as follows:

$$
N_{\overline{P A}}=\prod_{g=1}^{G} J_{g} .
$$

The comparison between the average effect of the group of treated countries, with the average effect of all the possible groups deriving from any potential combination of nontreated countries yields the $p$-value for the average effects. After ranking each yearspecific average trade reform effect in the placebo distribution, the yearly $p$-value of the average effect is thus computed as the ratio between the number of average placebo groups that display a higher effect than the actual group of treated countries, over the number of possible placebo averages. ${ }^{11}$

\section{Data, Measures and Sample Selection}

The first issue to address in our empirical analysis is the measurement of trade liberalization episodes. Following the cross-country growth literature we use the binary indicator of Sachs and Warner (1995) as recently revisited, corrected and extended by Wacziarg and Welch (2008). ${ }^{12}$ Using this index, a country is classified closed to international trade in any given year where at least one of the following five conditions is

\footnotetext{
${ }^{11}$ For a formal derivation of this methodology, see Cavallo et al. (2013).

${ }^{12}$ We use the extended Sachs and Warner index (SWI) to define the year of trade openness for both conceptual and practical reasons. First, the SWI is commonly used in the trade and growth literature and, as such, has been carefully tested, scrutinized and improved to deal with potential problems. Second, it is the only available indicator which has sufficient country and time coverage to build our treatment variable, i.e. that allow to define the year of trade liberalization, which is crucial to apply the SCM approach. Studies that used the SWI to assess the impact of trade liberalization include Billmeier and Nannicini (2013), Giavazzi and Tabellini (2005) and Wacziarg and Welch (2008).
} 
satisfied (otherwise, it will be considered open): (1) overall average tariffs exceed 40 percent; (2) non-tariff barriers cover more than 40 percent of its imports; (3) it has a socialist economic system; (4) the black market premium on the exchange rate exceeds 20 percent; (5) much of its exports are controlled by a state monopoly. Following Giavazzi and Tabellini (2005) we define a trade liberalization episode (or a "treatment") as the first year when a country can be considered open to international trade according to the criteria above, after a preceding period where the economy was closed to international trade. Finally, as discussed in Billmeier and Nannicini (2013), trade reforms may not occur suddenly, but there may be a gradual shift toward more liberal trade policies. If so, this means that our treated variable based on a binary indicator is measured with error. Note that this problem will introduce attenuation bias in our estimated reform effects, meaning that our results are underestimating the actual impact.

To measure health outcomes $\left(Y_{i t}\right)$, we use the under-5 mortality rate (per 1,000 live births), hereafter U5MR for brevity, from the United Nation Inter-agency Group for Child Mortality. ${ }^{13}$ The choice of this indicator of health is based on several grounds. First, as discussed extensively by Deaton (2006), it is a better health indictor than e.g. life expectancy, simply because life expectancy is a function of child and adult mortality. ${ }^{14}$ Second, the U5MR has the key advantage of being available on a yearly basis from 1960 for almost all the countries in the world. This is a key property for our identification strategy, because the SCM works with yearly data, and the dataset covers a period when many trade reforms happened. Third, from a conceptual point of view, the U5MR is a key indicator in the United Nations Millennium Development Goals (see Alkema et al. 2014)

\footnotetext{
${ }^{13}$ See: http://www.childmortality.org.

${ }^{14}$ See Lopez et al. (2000) for a critical discussion on how life expectancy can be estimated from information on child and adult mortality rates.
} 
and because improvements in child mortality happen at the bottom of the income distribution (Acemoglu et al. 2014), which made it especially relevant in this respect.

The vector of covariates $X_{j}$ used to identify the synthetic controls has been selected on the basis of previous (cross-country) studies on the determinants of health and child mortality (see, e.g., Charmarbagwala et al., 2004; Owen and $\mathrm{Wu}, 2007$; Hanmer et al., 2003). More specifically, the synthetic controls are identified using the following covariates: real per capita GDP (source: Penn World Table); population growth (Penn World Table); the fraction of rural population into total population (source: FAO); years of wars and conflicts based on Kudamatsu (2012) (source: Armed Conflict database, Gleditsch et al. 2002); female primary education (source: Barro and Lee, 2010); the average U5MR in the pre-treatment period (source: United Nations). Finally, in the robustness checks we also consider the Polity2 index from the Polity IV data set (see Marshall and Jaggers, 2007), to classify countries as autocracy or democracy, ${ }^{15}$ and data for agricultural policy distortions from the World Bank "Agricultural Distortion database" (see Anderson and Nelgen, 2008).

Our analysis focuses on trade liberalization in developing and emerging countries, because there is little variation in the key variables for rich countries. First, child mortality is much higher and more change has occurred in poorer countries than in rich. Second, the large majority of developed countries were already open to trade in 1960s as measured by the updated Sachs and Warner (1995) index.

We started from a dataset of about 130 developing and emerging countries. However, for about 33 of them, information related to the trade policy reform index is

\footnotetext{
15 The Polity 2 index assigns a value ranging from -10 to +10 to each country and year, with higher values associated with better democracies. We code a country as democratic $(=1,0$ otherwise $)$ in each year that the Polity2 index is strictly positive. A political reform into democracy occurs in a country-year when the democracy indicator switches from 0 to 1. See Giavazzi and Tabellini (2005) and Olper et al. (2014) for details.
} 
missing (see Wacziarg and Welch, 2008 for details). A further selection was based on the following criteria. First, the treated countries were liberalized at the earliest in 1970 , to have at least 10 years of pre-treatment observations to match with the synthetic control. ${ }^{16}$ Second, there exist a sufficient number of countries with similar characteristics that remain closed to international trade (untreated countries) for at least 10 years before and after each trade reform, so as to provide a sufficient donor pool of potential controls to build the synthetic unit and the placebo tests. Moreover, as suggested by Abadie (2013), we eliminated from the donor pool countries that have suffered large idiosyncratic shocks of the outcome variable during the studied period. ${ }^{17}$

A final critical issue is related to the criteria used to select the donor pool, namely the potential controls used to build each synthetic control. From this perspective we face a non-trivial trade-off. On the one hand, by considering in the donor pool only countries belonging to the same region of the treated unit could be a strategy that would allow having countries with a relatively strong degree of similarity with the treated unit, and that are likely to be affected by the same regional shocks as the treated unit. On the other hand, in our specific context this approach could present some problems. First, because it would imply few control countries in several SCM experiments, and would thus worsen the pretreatment fit and prevent the placebo tests. Second, the use of a donor pool with only countries that belong to the same region in an exercise that studies the macro effects of trade reforms, may violate the SUTVA assumption, because the spillover effects of trade liberalization in neighboring countries are likely more sever. Given these considerations, we do not impose further constraints in the selection of the donor pool, leaving the

\footnotetext{
${ }^{16}$ Abadie at al. (2010) show that the bias of the synthetic control estimator is clearly related to the number of pre-intervention periods. Therefore, in designing a synthetic control study it is of crucial importance to collect sufficient information on the affected unit and the donor pool for a large pre-treatment window.

${ }^{17}$ Countries excluded from the donor pool due to large idiosyncratic shocks in child mortality are: the Republic of Congo, Lesotho, Rwanda and Zimbabwe. Note, the inclusion of these country do not change at all the final outcomes and conclusions.
} 
selection of the best synthetic control to the SCM algorithm. However, as a robustness check, we also discuss the results obtained by imposing more restrictions in the choice of the donor pool.

Using these criteria, we ended up with a usable data set of 80 countries, of which 41 experienced a trade liberalization episode. ${ }^{18}$ The dataset has data from 1960 to 2010 . However, the time span used in the SCM is different for each country case-study based on the year of the liberalization. For each experiment, we use the years from $T_{0}-10$ to $T_{0}$ as the pre-treatment period to select the synthetic control, and the years from $T_{0}$ to $T_{0}+5$ and $T_{0}+10$ as the post-treatment periods, on which evaluating the outcome, where $T_{0}$ is the year of trade liberalization.

\section{Results}

\subsection{Quality of Synthetic Controls}

41 cases were analyzed in our SCM. The cases vary in the impact estimates but also in how close the treated and synthetic control are in the pre-treatment period ("fit") and in the balance in the covariates used to select the synthetic control ("balance") requirements for a successful SCM application. The SCM balance and pre-treatment fit for the 41 cases are summarized in Table $1 .{ }^{19}$ The pre-treatment "fit" is measured by the root mean square prediction error (RMSPE) reported in the first column, with a low RMSPE meaning a better pre-treatment fit. The "fit" is also reflected in the difference between the pre-treatment values for the outcome variable (U5MR) as measured at $\mathrm{T}_{0}-10$, $\mathrm{T}_{0}-5$ and $\mathrm{T}_{0}$ (see columns 2-4 of Table 1 ) for the actual country case and the synthetic

\footnotetext{
${ }^{18}$ More precisely, using these criteria we end up with 44 usable treated countries. However, for three countries it has been impossible to find a good counterfactual, due to their extreme high level of child mortality in comparison to the donor pool. These countries are: Mali, Niger, and Sierra Leone.

19 Table A1 in Appendix reports for each treated country the weight assigned by the SCM to all the countries constituting the donor pool of the synthetic control. For instance, "Synthetic Indonesia" is constituted by the weighted average of Uganda (33.8\%), Tunisia (23.2\%), Cameroon (12.7\%), Papua Nuova Guinea (11.7\%), Trinidad and Tobago (7.0\%), Philippines (6.6\%), and India (4.9\%).
} 
control. The numbers in columns 5-9 of Table 1 are indicators of the "balance". They present the values of the covariates of the actual country case and the synthetic control.

\section{----- Table 1 about here -----}

As can be seen from Table 1, we have classified the cases in 3 groups based on how well they satisfy the SCM requirements, with cases in group 1 doing best and group 3 worst. There are two criteria to take into account ("balance" and "fit") and for neither of them there is an established cut off point (like a p-value in statistics). Therefore, the classification of cases based on how well they satisfy the SCM requirements is unavoidably subjective to some extent.

Group 1 includes 16 cases which we evaluated as having the best combination of balance and fit. For all of them the RSMPE is less than 2 (and 12 with RMSPE $<1$ ) indicating a very good fit. The good pre-treatment fits in Group 1 are also illustrated in Figure 1. The black bold lines represent for each case the difference in the U5MR between the treated unit and the synthetic control. For all cases in Figure 1 these lines remain close to zero in the pre-treatment period, i.e. from the year $\mathrm{T}_{0}-10$ to $\mathrm{T}_{0}$, which illustrates the high pre-treatment similarity between the actual cases and their respective counterfactuals. Group 1 countries do also well in terms of the balance of the covariates used to design the synthetic control. The difference in the average value of the control variables of the treated country and the synthetic control are small.

\section{----- Figure 1 about here -----}

Group 2 has 11 cases. For all these cases the fit is also good: all have an RMSPE lower than 2 (and 5 with RMSPE $<1$ ). Some cases were left out of Group 1 because there are no data on female primary education (Burkina Faso, Cape Verde, Ethiopia, Guinee Bissau, Madagascar) and for the others there is a significant difference in the balance for one of the covariates. The good fit of these cases is illustrated in Figure 2. 
Group 3 includes the remaining 14 cases. These cases were least satisfactory for at least one of the SCM criteria. Either there was not a good balance in one or more control variables and/or the fit between treated and synthetic control was less than in the Group 1 and 2 countries (for all the Group 3 countries the RMSPE is higher than 2).

In the rest of this paper we will focus on results of the Group 1 and Group 2 cases only, and drop Group 3 cases because we consider them as not sufficiently satisfying the SCM requirements. ${ }^{20}$ Furthermore, to test for robustness of the SCM results for SCM selection criteria, in the rest of the paper we first present the Group 1 results and then analyze how the average results and the distribution of the effects change when we also include Group 2 countries.

\subsection{Average and Country-level Effects}

Table 2 presents the impacts of trade liberalization on child mortality for each of the countries in Group 1 and 2, with the countries ranked from the country with the largest reduction in child mortality (Peru) to the country with the largest increase in child mortality (South Africa) at year $\mathrm{T}+10$. Table 2 reports the levels of under-five mortality rate at $\mathrm{T}+5$ (column 6 ) and $\mathrm{T}+10$ (column 7 ), the treatment effect calculated from comparison with the post-treatment outcome of the treated unit with its synthetic control after five $\left(T_{0}+5\right)($ column 8$)$ and ten years $\left(T_{0}+10\right)$ (column 9), and the significance of the treatment effects with the $p$-value (column 10) as obtained from the placebo tests. ${ }^{21}$

\footnotetext{
${ }^{20}$ Note that our choice to drop Group 3 cases is more conservative (or prudent) than criteria used in several previous papers using the SCM. For example, Acemoglu et al. (2016) distinguish between reliable and notreliable synthetic controls by using a threshold of $\sqrt{3}$ times the average RMSPE of all the SCM experiments. If we would have used this threshold, we would have included all the SCM experiments with a RMSPE < 4.6, which means that 8 countries of Group 3 would have been included (in addition to all the country cases of Group 1 and 2).

${ }^{21}$ The $p$-values of placebo tests correspond to the graphical representation of Figures 1 and 2 . The bold black lines report the outcome difference between the treated and the synthetic control, while the grey dash
} 
What is immediately clear from Table 2 is the strong heterogeneity of the reform effects. The 10-year impacts range from $-35 \%$ (Peru) to $+52 \%$ (South Africa). For the vast majority ( $75 \%$ of Group 1 cases (12 of 16) and $81 \%$ of Group $1+2$ cases (22 out of 27)) we estimate that trade liberalization reduced child mortality. Not all of these effects are significant. There are more than 8 cases in Group 1 and 13 cases in Group 1+2 for which the estimated reduction is larger than $10 \%$ (including Peru, Guatemala, Tanzania, El Salvador, Ghana, Tunisia, Nicaragua, Indonesia, etc). While in South Africa and Mauritania there was a strong increase in child mortality $(+52 \%$ and $+24 \%)$, they are the only cases for which the SCM shows an increase that is larger than $10 \%$.

Table 3 summarizes the significant effects for $p$-value cut-offs at 0.10 and at $0.15 .^{22}$ Not surprisingly, the cases at the top and bottom of Table 2, where the estimated effects are largest, have the lowest $p$-value. In Group 1, half the cases (8 out of 16) have a $p$-value lower than 0.10 (and 11 cases a $p$-value $<0.15$ ). From these, in 7 cases $(11$ for $p$-value < $0.15)$ trade liberalization reduced child mortality and in only 1 case $(2$ for $p$-value $<0.15)$ it worsened child mortality.

\section{----- Table 3 about here -----}

Extending the analysis to the larger sample of Group 1+2 countries reinforces these results. $41 \%$ of the cases (11 out of 27 ) have a $p$-value lower than 0.10 (and 15 cases a $p$-value $<0.15)$. From these, in 10 cases $(13$ for $p$-value $<0.15)$ trade

\footnotetext{
lines report the outcome differences between each fake treated country from the donor pool and their synthetic control in the placebo tests.

${ }^{22} \mathrm{We}$ also looked at the p-value $<0.15$ in the significance evaluations because the placebo test for several case studies suffers from a low number of available fake experiments. This is because, in order to avoid outliers, we consider for the p-value computation only those placebo effects where the RMSPE produced by the synthetic control is set within an interval with a maximum of five times the RMSPE of the actual treated country.
} 
liberalization reduced child mortality and in only 1 case $(2$ for $p$-value $<0.15)$ it worsened child mortality.

The level of significance of the trade liberalization effect for these country-cases is estimated based on in-space placebo tests, as illustrated by Figures 1 and 2 . The dashed lines in these figures represent results of placebo tests when treatment is assigned to other countries in the donor pool.

To further test the robustness of our results of single country-cases, we follow Abadie, Diamond and Hainmuelle (2015) by also running in-time placebo tests. These are fake experiments where the treatment is assigned in a period falling well before the real one. If a treated country shows a similar effect in the in-time placebo test to that obtained with the actual treatment, then it is likely that the estimated effect is not attributable to trade liberalization. In contrast, if a country does not show any relevant effect in the intime placebo, then we can be more confident in attributing the estimated effect to trade reforms. Figure 3 presents two examples of the results of our in-time Placebo tests for the cases of Nicaragua (a Group 1 country) and Turkey (a Group 2 country), two countries for which the SCM showed large effects of trade liberalization (-17\% and $-34 \%$ respectively). In both cases we imposed trade liberalization in the placebo test ten year before the actual occurrence. The results of the in-time placebo test clearly show that there is no evidence of any trade reform effect on the evolution of child mortality for none of the two countries, confirming the robustness of our findings. ${ }^{23}$

\section{----- Figure 3 about here -----}

Figure 4 illustrates the aggregated average effect of trade liberalization on child mortality for Group 1 and Group 1+2. The vertical line represents the year of trade liberalization $\left(T_{0}\right)$. Before trade liberalization, the Group 1 and Group $1+2$ indicators are

\footnotetext{
${ }^{23}$ Results of in-time placebo tests for the other countries can be obtained from the authors.
} 
close to zero, reflecting the high quality of the synthetic controls in Group 1 and 2 as discussed above. After trade liberalization, average child mortality rates of the treated countries falls below the child mortality rates of the synthetic control. On average, trade liberalization reduced child mortality by $5.29 \%$ after year 5 and $6.48 \%$ after year 10 in Group 1 (p-value <0.01) and by $5.95 \%$ after year 5 and $8.96 \%$ after year 10 in Group $1+2$ (p-value $<0.10)$.

\section{----- Figure 4 about here -----}

In summary, these results imply that, on average, trade liberalization reduced child mortality but that there is significant heterogeneity in the effects. In the majority of the cases child mortality decreased and only in a few cases did child mortality increase. These conclusions hold both with the restricted (Group 1) sample and the extended (Group 1+2) sample.

In the rest of the paper we will (a) further test the robustness of these findings, (b) analyse whether confounding factors may explain some of the results and (c) analyse whether we can identify potential reasons for the strong heterogeneity of the effects.

\section{Robustness Tests 1: Stable Unit Treatment Value Assumption (SUTVA)}

A key issue in our identification strategy is the SUTVA assumption, i.e. that the treatment status of one unit does not affect the potential outcomes of the other (control) units. If this condition is not satisfied, the size of the effects could be either over or under estimated.

In the specific context of our analysis, the existence of such (potential) spillover effects are not obvious because the impact of trade liberalization exerts on child mortality tend to be only indirect. Clearly, the existence of spillover effects would be more likely if the outcome variable under investigation would be, for example, trade flows or foreign 
direct investment, instead of child mortality. ${ }^{24}$ However, such spillover effects are less likely in the case of child mortality.

Still, to be on the safe side, we re-ran the SCM experiments by excluding from the donor pool those countries that share a national border with the treated country, so that the possible spillover effects will be attenuated. The results for these SCM experiments are in Table A2 in Appendix). Excluding countries that share a national border from the donor pool affects the results for 8 countries. We have highlighted these countries in bold in Table A2. For most of the cases (5 out of 8 ), the numbers indicate a larger reduction (or a smaller increase) in child mortality. The average reduction in child mortality for Group 1 is $7.8 \%$ ten years after trade liberalization (compared to a reduction of $6.4 \%$ in the initial estimations); for Group $1+2$ the effect increases from $-9.0 \%$ to $-13.2 \%$.

The largest change is for Mauritania, where the previously estimated strong increase in child mortality following trade liberalization (24.14\%) shrinks to almost zero $(0.85 \%)$, and becomes non-significant. It is the only one of the 8 countries where the significance category (as summarized in Table 3) changes. This means that, after taking into account these possible violations of SUTVA, only South Africa remains as a case where trade liberalization was associated with a significant increase in child mortality for both Group 1 and Group 1+2, and for any meaningful p-value.

\section{Robustness Tests 2: Other Shocks}

If other important changes affecting child health (and that are not (fully) captured by the SCM) occurred around the time of trade liberalization, our estimated impacts could be the result of these "other changes" rather than that of trade reforms. In the period and the countries that are covered by our analysis, two important changes occurred (in some of the

\footnotetext{
${ }^{24}$ If trade liberalization in one country led to growing trade, trade in other, and especially in geographical proximate countries, would change as well.
} 
countries) that may have affected child mortality evolution: major political reforms (democratization) and the spread of HIV/AIDS. In this section we discuss both factors and try to assess to what extent they may affect our results; and to what extent they may help to explain the observed heterogeneity of the effects.

\subsection{Political Reforms}

Several studies show empirically that the switch from autocracy to democracy may affect health outcomes (Besley and Kudamatsu, 2006; Kudamatsu, 2012; Pieters et al., 2016). Other studies argue theoretically (Zissimos, 2014) or show empirically (Giavazzi and Tabellini, 2005) that trade and political reforms are often interrelated in developing countries.

A related, but distinct, issue is that the nature of the political system could affect the trade liberalization effects. If there are no confounding effects due to political changes (and thus no bias in our estimated numbers) it may be that some political systems are more conducive to for example protecting the poor against potential negative effects of trade liberalization or enhance the poor's capacity to benefit from new opportunities due to trade liberalization. This could then affect child mortality. Standard political economy arguments based on the median voter model suggest that, on average, democracies are more likely to contribute to pro-poor outcomes than autocracies.

We will consider both issues. A simple way to check whether our findings suggest that the nature of the political regime interacts with the trade reform effects is to aggregate the SCM results according to the countries' political regime. We therefore classify the countries with significant reduction of the reform effect in Group 1 and in Group 1+2 in 
three (not overlapping) groups, using the Polity2 index of democracy. ${ }^{25}$ We classify these countries based on the political regime in place in the years "close to" the economic transition, which we define as the five years before and after trade liberalization. ${ }^{26}$

We compare the trade liberalization effects which occurred under three different political regimes: (i) democracies, (ii) autocracies, ${ }^{27}$ and (iii) close to political reforms (for all countries in our analysis "political reform" means democratization, i.e. the switch from autocracy to democracy). ${ }^{28}$ Figure 5 illustrates the results. ${ }^{29}$ The three lines represent the (aggregated) average effect in countries that experienced the trade liberalization in consolidated democracies (triangle line), in autocracies (circle line) and near political reforms (diamond line). All the average effects proved to be, on average, significant, with a p-value $<0.01$ for Democratic and Transition countries (both in Group 1 and Group 1+2), and a p-value $<0.05$ for Autocratic countries.

\section{----- Figure 5 about here -----}

A first observation is that there is a similar decline in child mortality in all three groups. The three effect lines move similarly beyond the time of trade liberalization. In all political regimes the average effect is a reduction of child mortality between $15 \%$ and $30 \%$. This suggest that it is not political reforms (democratizations) that are driving our measured effects of trade liberalization on child mortality, ceteris paribus.

\footnotetext{
${ }^{25}$ Note, we considered only countries with significant reform effects because the relevant question here is to understand the extent to which the magnitude of the estimated effect is really attributable to trade liberalization and not to political reform.

${ }^{26}$ The choice of using five years before and five years after trade liberalization, instead of the whole period of each analysis (i.e. ten years before and ten years after trade liberalization) is to better isolate the political condition near the treatment period. However, when using the whole period (ten years), the main results are not affected.

27 See Table 4 for the composition of the political regime groups.

${ }^{28}$ We use the same approach as Persson and Tabellini (2008) to determine the year of democratization with the polity 2 variable.

${ }^{29}$ Also here the aggregation is based on equation (5) and the value of child mortality is normalized by setting child mortality of the treated country to be equal to 1 in the year of trade reform $\left(T_{0}\right)$.
} 
A second observation is that the size of the effect differs between democracies and the other two groups. The reduction in child mortality is largest for the democratic countries experiencing trade liberalization: their average reduction in child mortality after ten years is around $27 \%$ for Group 1 and almost $30 \%$ for Group $1+2$. In autocratic countries or countries where trade liberalization occurred close to political reforms the average reduction in child mortality was between $16 \%$ and $19 \%$, substantially less than in democratic countries. ${ }^{30}$ The result that trade liberalization reduces child mortality more in democracies than in autocracies is consistent with the hypothesis that the poor are more likely to benefit from trade liberalization in a democratic regime. ${ }^{31}$

\subsection{HIV/AIDS}

The spread of HIV/AIDS has affected mortality in many countries, and especially in some sub-Saharan African (SSA) countries after 1990. As with political reforms (Section 6.1) the spread of HIV/AIDS may affect our results in two ways. The spread of HIV/AIDS may occur simultaneously with trade liberalization and thus cause a bias in our estimated effects of trade liberalization. There may also be an interaction between trade liberalization and HIV/AIDS diffusion. Oster (2012) empirically showed how trade in SSA has stimulated the spread of HIV/AIDS, particularly in Eastern and Southern Africa.

\footnotetext{
${ }^{30}$ Our results and conclusions are robust if we (instead of using only countries with a significant reduction in child mortality) include all the countries of Group 1+2. The first issue in the robustness test (that countries experiencing democratization near the trade liberalization do not have a stronger effect than the other two groups) remains. The second issue (that trade liberalization effects are stronger in democracies) depend somewhat on whether South Africa is included or not. South Africa is a very special case because of two reasons. First, as we explain in Section 6.2, the strong increases in child mortality in South Africa are most likely caused by the dramatic spread of HIV in the country, which makes it a very special case. Second, although South Africa is classified as a permanent democracy (since 1960) according to the Polity 2 index, the country did experience a major political liberalization (democratization) at the end of the Apartheid regime (in 1990-94) which was quasi-simultaneous with the trade liberalization in 1991. Both arguments could be used to leave South Africa out of the robustness test.

31 This is somewhat different from Giavazzi and Tabellini (2005) who found that when economic liberalization preceded the political reform, countries perform better in term of GDP growth -- but we know that there is not necessarily a direct link between GDP growth and child mortality (see Deaton, 2003).
} 
Unlike for political reforms, we cannot develop a good test for whether the spread of HIV has affected our results because there is no good dataset for HIV infections for a sufficiently long period of time (e.g. to also cover the pre-treatment periods). Data on HIV are only available in a consistent way since 1990 which makes it impossible to integrate it into the SCM analysis.

\section{---- Table 4 about here -----}

That said, a comparison of HIV/AIDS infections between countries that liberalized trade does provide some interesting insights. Table 4 presents the average HIV prevalence (as a share of the population between 15 and 49 years) in the post-treatment period of our SCM analysis for the three groups of countries (significant reduction, no significant effect, and significant increase of child mortality). The HIV prevalence is much higher where child mortality increased (at 9.7\%) than in the other groups (averages at 1.9\%, 1.3\% and $1.7 \%)$. The very high $(9.7 \%)$ post-liberalization infection rate is in South Africa, which is the only country where there is a very strong increase of child mortality after the trade liberalization $(+52 \%)$. HIV prevalence increased from $1 \%$ in 1990 to $25 \%$ in 2000 (Karim and Karim, 1999; South Africa Department of Health, 2005). Figure 6 illustrates the very strong correlation between the increase in child mortality and the spread of HIV in the post-liberalization period in South Africa. With the available data we cannot use the SCM approach to test whether trade liberalization has contributed to this spread (as argued by Oster, 2012), but it is likely that these dramatic changes in HIV prevalence may explain why South Africa stood out as the only country where child mortality increased significantly with trade liberalization.

The impact on the estimated effects for the other countries are likely much smaller, if any. Besides South Africa, the average HIV prevalence in the post-liberalization period was high only in Tanzania (7.7\%) and Ivory Coast (5.3\%) - see Table A3 in Appendix. 
However, as Figure 6 illustrates, unlike in South Africa, the HIV prevalence stabilized in both Tanzania and Ivory Coast in the post-liberalization period.

\section{----- Figure 6 about here -----}

For both countries the SCM results indicate that trade liberalization caused significant reductions in child mortality (consistent with the rapid declines illustrated in Figure 6 after trade liberalization). In the other SSA countries in Group 1 and 2, the HIV prevalence was much lower after trade liberalization. For example, while Botswana was later hit strongly by HIV/AIDS, its trade liberalization was in 1979, well before the rapid spread of HIV/AIDS. Finally, in Mauritania, the spread of HIV/AIDS has been one of the lower in SSA countries, ${ }^{32}$ and is thus unlikely the cause of the increase in child mortality. However, as we showed earlier, this result for Mauritania was not robust to the SUTVA test and became close to zero when controlling for it (see Section 5). These observations suggest that the impact of HIV/AIDS in other countries than South Africa on the estimated effects has been low and/or that, if anything, the estimated improvement in child health is biased downward.

In summary, while this comparison and discussion obviously does not provide a formal test of the HIV effect, the data in Table 2 are consistent with the hypothesis that the unique SCM result of South Africa (where a strong increase in child mortality followed trade liberalization) can at least be partially attributed to the dramatic spread of HIV which occurred around the same period, and which may have been stimulated by trade (liberalization), as Oster (2012) suggests.

Since we cannot formally test for the causal interaction of trade liberalization, HIV spread and child mortality, one could make a case that we should drop the South African case from our analysis. The opposite argument is that it should be included because it

\footnotetext{
${ }^{32}$ Mandzik and Young (2014) attributed the low HIV/AIDS diffusion in Mauritania to religion, i.e. the large prevalence of Muslims in that country.
} 
shows that trade liberalization may have negative effects on health if it stimulates the cross-border spread of diseases to the extent that they may dominate more positive trade effects. For the results as presented so far, the main impact of excluding South Africa, is that the average trade liberalization effects will be more positive for both Group 1 and Group 1+2: the average $\mathrm{T}+10$ effect increases from $6.4 \%$ to 10.3 for Group 1 and from $8.9 \%$ to $11.3 \%$ for Group 1+2. In the rest of the analysis, we will indicate how the South African cases affects the results.

\section{Causes of Heterogeneity: Incomes and Agricultural Policy}

In this section we further analyze potential factors that may affect the relationship between trade liberalization and child mortality and thus may also contribute to explain the observed heterogeneity of the measure effects. In particular, we test if income levels and agricultural policies (with many poor people working in agriculture) influence the impact of trade liberalization on child mortality.

\subsection{Income Level}

A country's income level, or level of development more generally, may influence the trade liberalization effects because low income countries typically have weak institutions and poor infrastructure. A weak institutional framework, poor infrastructure, and limited private and public resources in general may constrain the reallocation of production factors (including poor people's labor) to be more efficiently used in order to realize the gains from trade (Bardhan, 2006). For the poor for whom child mortality is highest, these factors may also constrain health policies to be effective in response to a changed economic and social environment. 
To check whether our findings are consistent with the argument that the effect of trade liberalization on child mortality may be influenced by the level of development (income), we divided the sample of treated countries in two groups: countries with below median ("lower") income levels and countries with above median ("higher") income levels, at the time of trade liberalization.

\section{----- Figure 7 about here -----}

The results in Figure 7 clearly show that the reduction of child mortality in countries with higher income at the time of trade liberalization was indeed larger than in lower income countries, in both Group 1 and Group 1+2. After 6 to 10 years, the difference was around 5\% points. Child mortality in the higher-income group was on average around 5\% lower than the counterfactual in the lower-income country group while it was around $10 \%$ lower in the higher-income group (with the reduction somewhat stronger in Group 1+2). ${ }^{33}$

These results are consistent with the argument that the effect of trade liberalization on child mortality is more positive in countries that, at the time of the reform, have a better institutional framework, better infrastructure, and more resources to allow the reallocation of production factors (including poor people's labor) to be more efficient to realize the gains from trade.

\subsection{Agricultural Policy}

Many of the poorest people in the world are employed in agriculture, either as smallholder farmers or as farm workers, and live in rural areas. This makes agriculture and rural areas the main social location of child mortality. One can therefore imagine that a trade liberalization that directly changes the profitability in agriculture could have a

\footnotetext{
${ }^{33}$ Note, excluding South Africa (one of the higher income countries) because of its specific situation (see Section 6.2) would reinforce these results, i.e. it would make the gap in trade liberalization effects between lower and higher income countries larger.
} 
stronger effect on child mortality as it directly influences an important source of poor people's income.

In many countries in the world governments heavily intervene in food and agricultural markets. Studies have shown that these government interventions are not random but follow a systematic pattern: rich countries subsidize their farmers while poor countries tend to tax their agricultural sectors (Krueger et al. 1988; Anderson 2010;). This was especially the case in the 1970s and 1980s before many agricultural policy reforms were implemented around the world (Anderson et al. 2013). Since many agricultural products are traded, these policy reforms have often coincided with trade policy reforms (see Olper et al. 2014). Therefore the extent to which trade liberalization has affected farmers, e.g. through the removal of export taxes, may help to explain the impact on the poor, and thus on child mortality.

There is casual evidence from African, Asian and Latin American countries in Group $1+2$ to support this argument and our SCM results. For example, in Ghana (with a reduction of $17.9 \%$ in child mortality - see Table 2), trade liberalization in 1985 reduced export taxation on key agricultural commodities (in particular cocoa which is a very important commodity for Ghana) and this coincided with an overall liberalizing of its agricultural policy (Thomas 2006). These reforms reduced agricultural taxation and contributed to a significant reduction in poverty and inequality in Ghana's rural areas (Coulombe and Wodon, 2007). In several countries in North Africa and the Middle East where trade liberalizations reduced child mortality, such as Tunisia $(-17.5 \%)$ and Turkey $(-33.9 \%)$, it caused a reduction in taxation of agriculture and reduced rural poverty (Anderson and Nelgen, 2013; Chemingui and Thabet 2003).

Similarly, in Sri Lanka (with a reduction of $28.1 \%$ in child mortality) the trade liberalization caused a reduction of the taxation of agricultural export crops, especially 
tea, coconuts and rubber. Taxation of these main export products fell from around $40 \%$ before the trade liberalization to $20 \%$ after the reforms, contributing to agricultural productivity growth and significant poverty reduction (De Silva et al. 2013; Karunagoda et al. 2011). Also in Latin America, in several countries where trade liberalization reduced child mortality according to our estimations, such as Mexico (-18.5\%) and Brazil (-27.2 $\%)$, trade liberalizations reduced taxation of agriculture (Anderson and Nelgen, 2013).

In order to test more formally whether our estimated trade liberalization effects are correlated with changes in agricultural policy, we make use of the Nominal Rate of Assistance to agriculture (NRA) from Anderson and Valenzuela (2008) and Anderson and Nelgen (2013). The NRA is an indicator of the extent of subsidization (positive NRA) or taxation (negative NRA) of the agricultural sector through government policies (including border trade policies, such as tariffs and non-tariff barriers).

To check the role of and relationship with agricultural policy, we classify our trade liberalizing countries in two different groups: one group where the NRA increased more than the mean NRA change (and where farmers thus (at least potentially) benefited more than average from trade liberalization) and one group where the NRA increased less than the mean. ${ }^{34}$

\section{---- Figure 8 about here -----}

The results in Figure 8 show that the reduction of child mortality in countries with higher NRA growth - hence a stronger reduction in agricultural taxation after the trade liberalization - was significantly stronger than in lower NRA growth countries. The difference between both groups of countries is large. After 5 years, the difference was around $8 \%$ points (11\% compared to $3 \%$ reduction) and after 10 years the difference was

\footnotetext{
${ }^{34}$ Figure 8 presents the results for Group 1+2. It was not possible to do the analysis for Group 1 alone since there were too few observations with NRA estimates in the Anderson and Nelgen (2013) dataset.
} 
$12 \%$ points ( $16 \%$ compared to $4 \%$ reduction in child mortality) - all significant at $p$ value $<0.01 .^{35}$

Overall, these results are consistent with the argument that poor people in developing countries (which are the ones primarily confronted with child mortality) benefit from trade liberalization more if it benefits the sectors they work in, in this case agriculture, as the poor are still mainly concentrated in rural areas and depending on agriculture for their income. This is also consistent with the more general argument that what matters for the reduction of child mortality (and reduction of poverty more generally) is not just trade reform per se, but the nature of the trade reform and which sectors it affects (Ravaillon and Chen, 2007).

\section{Conclusions}

We study the effect of trade liberalization on child mortality using data from emerging and developing countries over the 1960-2010 period. To capture possible heterogeneity of effects, we use the Synthetic Control Method (SCM) for comparative case studies. We use data on 41 cases of trade liberalization during the last half-century. The SCM allows to construct counterfactuals and to control for the time-varying nature of unobserved heterogeneity.

We classified the SCM analyses for the 41 investigated cases into three groups based on how they satisfied the SCM requirements (covariates balance and pre-treatment fit), with Group 1 doing best and Group 3 worst. We focused in the analysis on Group 1 cases and used Group 2 cases to see how consistent the results were if one used different selection criteria. Overall the results in Group 1 and the enlarged Group 1+2 yield very similar results.

\footnotetext{
${ }^{35}$ Excluding South Africa (which is in the group of the lower NRA growth countries) because of its specific situation (see Section 6.2) would reduce the gap in trade liberalization effects between lower and higher NRA growth countries.
} 
The results indicate that, on average, trade liberalizations reduced child mortality, but with important heterogeneity at the country level, i.e. the effects differ significantly across cases. In around half of the cases there was a significant reduction in child mortality following trade liberalization, with around one-third of the cases showing a reduction of more than $15 \%$ after 10 years. In almost half of the cases there was no significant effect.

Only two cases showed a significant increase in child mortality. One of these cases did not satisfy robustness tests on some key assumptions of the SCM approach. The remaining case where child mortality increased very strongly (more than 50\%) after trade liberalization was South Africa in the 1990s. Further analysis suggests that this is most likely to an important extent caused by the dramatic spread of HIV/AIDS in South Africa during this period. Other studies have suggested that trade has contributed to the spread of HIV/AIDS in southern and eastern Africa, but due to lack of data we could not test with the SCM the extent to which trade liberalization affected this spread of HIV/AIDS.

Our analysis also showed that several factors influenced the substantial heterogeneity in the benefits of trade liberalization for child health (reduction in child mortality). Political regimes, income levels and agricultural policy all affected the estimated effects. The reduction in child mortality caused by trade liberalization was stronger in democracies than in autocracies (and robustness tests did not support the argument that the political reforms were the cause behind the mortality changes). The benefits of trade liberalization in terms of reducing child mortality were stronger in countries with higher income levels.

Finally, both casual evidence and statistical analysis suggest that the extent to which trade liberalization reduced taxation on the agricultural sector played a crucial role in its effect on child mortality. Agriculture is the main source of employment and income for the poorest people who are disproportionately confronted with child mortality. Our 
results suggest that in cases where trade liberalization had a stronger positive effect on returns to agriculture (through improving the policy environment) child mortality reduced much more than where this was less the case.

\section{References}

Abadie, A. (2013). Using Synthetic Controls to Evaluate an International Strategic Positioning Program in Uruguay: Feasibility, Data Requirements, and Methodological Aspects. Working Paper, Mimeo.

Abadie, A. and Gardeazabal, J. (2003). The Economic Costs of Conflict: A Case Study of the Basque Country. American Economic Review 93(1), 113-132.

Abadie, A., Diamond, A. and Hainmueller, J. (2010). Synthetic Control Methods for Comparative Case Studies: Estimating the Effect of California's Tobacco Control Program. Journal of the American Statistical Association 105(490), 493-505.

Abadie, A., Diamond, A and Hainmueller, J. (2015). Comparative Politics and the Synthetic Control Method. American Journal of Political Science 59(2), 495-510.

Acemoglu, D., Naidu, D., Restrepo, P., Robinson, J.A. (2014). Democracy, Redistribution and Inequality, Ch. 21 in Anthony Atkinson and Francois Bourguignon (Eds.), Handbook of Income Distribution, Volume 2: 1885-1966.

Acemoglu, D., Johnson, S., Kermani, A., Kwak, J. and Mitton, T. (2016). The value of connections in turbulent times: Evidence from the United States. Journal of Financial Economics 121, 368-391.

Alkema, L., New, J.R., Pedersen, J. and You, D.. (2014). Child Mortality Estimation 2013: An Overview of Updates in Estimation Methods by the United Nations InterAgency Group for Child Mortality Estimation. PLoS ONE 9(7), e101112. 
Anderson, K. (2010). Krueger, Schiff, and Valdés Revisited: Agricultural Price and Trade Policy Reform in Developing Countries since 1960, Applied Economic Perspectives and Policy 32(2), 195-231.

Anderson, K., Rausser, G. and Swinnen, J. (2013). Political Economy of Public Policies: Insights from Distortions to Agricultural and Food Markets. Journal of Economic Literature 51(2), 423-477.

Anderson, K. and Nelgen, S. (2013). Updated National and Global Estimates of Distortions to Agricultural Incentives, 1955 to 2011. (The World Bank: Washington, DC), June.

Anderson, K. and Valenzuela, E. (2008). Estimates of Distortions to Agricultural Incentives, 1955 to 2007 (The World Bank: Washington, DC). www.worldbank.org/agdistortions.

Anderson, K., and Valdés, A. (eds.) (2008). Distortions to Agricultural Incentive in Latin America. The World Bank: Washington, DC.

Anukriti, S. and Kumler, T. (2014). Tariffs, Social Status, and Gender in India. IZA Discussion Paper No. 7969, February 2014.

Bardhan, P. (2006). Globalization and Rural Poverty. World Development 34(8), 1393-1404.

Barro, R. and Lee, J-W. (2010). A New Data Set of Educational Attainment in the World, 1950-2010. NBER Working Paper No. 15902.

Bertrand, M., Duflo, E. and Mullainathan, S. (2004). How Much Should We Trust Differences-In-Differences Estimates? Quarterly Journal of Economics 119(1), 249275.

Besley, T. and Kudamatsu, M. (2006). Health and Democracy, American Economic Review 96 (2), 313-318. 
Billmeier, A. and Nannicini, T. (2013). Assessing economic liberalization episodes: A synthetic control approach, Review of Economics and Statistics 95(3), 983-1001.

Blouin, C., Chopra, M. and van der Hoeven, R. (2009). Trade and social determinants of health. The Lancet 373, 502-07.

Cavallo, E., Galiani, S., Noy, I. and Pantano, J. (2013). Catastrophic Natural Disasters and Economic Growth, The Review of Economics and Statistics 95(5): 1549-1561.

Charmarbagwala, R., Ranger, M., Waddington, H. and White, H. (2004). The determinants of child health and nutrition: A meta-analysis. OED Working Paper Series. Operations Evaluation Department, The World Bank, Washington, DC.

Chege, C.G.K., Andersson, C.I.M. and Qaim, M. (2015). Impacts of Supermarkets on Farm Household Nutrition in Kenya. World Development 72 (1), 394-407.

Chemingui, M. A. and Thabet, C. (2003). Agricultural Trade Liberalization and Poverty in Tunisia: Macrosimulation in a General Equilibrium Framework. African Trade Policy Centre (ATPC), Working in Progress No 67.

Cornia, G.A., Rosignoli, S. and Tiberti, L. (2008). Globalization and Health. Impact pathways and recent evidence. UNU-WIDER Research Paper No. 2008/74.

Coulombe, H. and Wodon, Q. (2007). Poverty, livelihoods, and access to basic services in Ghana. Ghana CEM technical review growth workshop, Accra, May 2-3, 2007.

Deaton, A. (2003). Health, Inequality, and Economic Development. Journal of Economic Literature 41(1), 113-158

Deaton, A. (2004). Health in an Age of Globalization, Brookings Trade Forum 2004. Globalization, Poverty, and Inequality: 83-130.

Deaton, A. (2006). Global Patterns of Income and Health: Facts, Interpretations, and Policies, WIDER Annual Lecture 10, UNU World Institute for Development Economics Research. 
Dollar, D. (1992). Outward-Oriented Developing Economies Really Do Grow More Rapidly: Evidence from 95 LDCs, 1976-1985, Economic Development and Cultural Change 40(3), 523-44.

FAO (2012). The State of Food Insecurity in the World 2012: economic growth is necessary but nor sufficient to accelerate reduction of hunger and malnutrition, FAO, Rome.

Fledderjohann, J. Vellakkal, S., Khan, Z., Ebrahim, S. and Stuckler, D. (2016). Quantifying the impact of rising food prices on child mortality in India: a crossdistrict statistical analysis of the District Level Household Survey. International Journal of Epidemiology 45(2), 554-564.

Filmer, D., Pritchett, L. (1999). The impact of public spending on health: does money matter? Social Science \& Medicine 49, 1309-1323

Frankel, J. and Romer, D. (1999). Does trade cause growth? American Economic Review 89 (3), 379-399.

Giavazzi, F. and Tabellini, G. (2005). Economic and political liberalization, Journal of Monetary Economics 52, 1297-1330.

Gleditsch, N. P., Wallensteen, P., Eriksson, M., Sollenberg, M. and Strand, H. (2002). Armed Conflict 1946-2001: A New Dataset. Journal of Peach Research 39, 615-637. Goldberg, Pinelopi K. and Pavcnik, N. (2004). Trade, Inequality, and Poverty: What Do We Know? Evidence from Recent Trade Liberalization Episodes in Developing Countries, Brookings Trade Forum 2004. Globalization, Poverty, and Inequality: 223-269.

Goldberg, P.K. and Pavcnik, N. (2007). Distributional Effects of Globalization in Developing Countries, Journal of Economic Literature 45(1), 39-82. 
Hanmer, L., Lensink, R., \& White, H. (2003). Infant and Child Mortality in Developing Countries: Analyzing the Data for Robust Determinants. Journal of Development Studies, 40(1),101-118.

Harrison, A. (2006). Globalization and Poverty, NBER Working Papers 12347, National Bureau of Economic Research.

Headey, D. D. (2014). Food prices and poverty reduction in the long run. IFPRI discussion papers 1331, International Food Policy Research Institute (IFPRI).

Karim, Q.A. and Karim S.A. (1999). Epidemiology of HIV infection in South Africa. Aids. 13(6), 4-7.

Kreif, N., Grieve, R., Hangartner, D., Turner, A., Nikolova, S. and Sutton, M. (2016). Examination of the Synthetic Control Method for Evaluating Health Policies with Multiple Treated Units. Health Economics. 25(12), 1514-1528.

Krueger, A. O., Schiff, M. and Valdés, A. (1988). Agricultural Incentives in Developing Countries: Measuring the Effect of Sectoral and Economy-wide Policies, World Bank Economic Review (2) 3, 255-272.

Kudamatsu, M. (2012). Has Democratization Reduced Infant Mortality in Sub-Saharan Africa? Evidence from Micro Data, Journal of the European Economic Association, 10(6), 1294- 1317.

Kumar, K., Ram, F. and Singh, A. (2013). Public health spending on infant and child mortality in India during the years 1980-2006, The Lancet, Volume 381, Special Issue, S76, 17.

Levine, D.I. and Rothman, D. (2006). Does trade affect child health? Journal of Health Economics 25, 538-554. 
Lopez, A.D., J.A. Salomon, O. Ahmad, C.J. Murray, and D. Mafat (2000). Life Tables for 191 Countries: Data, Methods, and Results, GPE Discussion Paper 9, WHO: Geneva.

Mandzik, A. and Young, A.T. (2014). Religion and AIDS in Sub-Saharan Africa: Unbundling Religious Institutions, Working Paper, West Virginia University.

Marshall, M. G., and Jaggers, K. (2007). Polity IV Project: Dataset Users' Manual. Arlington: Polity IV Project.

Martens, P., Akin, S.-M., Maud, H. and Mohsin, R. (2010). Is globalization healthy: a statistical indicator analysis of the impacts of globalization on health. Globalization and Health, 6 (16), 1-14.

Mukerjee, N. and Kreckhaus, J. (2011). Globalization and human well-being. International Political Science Review, 33(2), 150-170.

Nissanke, M. and Thorbecke, E. (2006). Introduction: The Impact of Globalization on the World's Poor. World Development, 34 (8), 1333-1337.

Nunn, N. and Trefler, D. (2014). Domestic Institutions as a Source of Comparative Advantage. Ch. 5 in G. Gopinath, E. Helpman and K. Rogoff (Eds.), Handbook of International Economics, Elsevier, Amsterdam: 263-315.

Oberländer, L., Disdier, A-C. and Etilé, F. (2016). Globalisation and national trends in nutrition and health - a grouped fixed effects approach to inter-country heterogeneity. Health Economics. 26 (9), 1146-1161.

Olper, A., Fałkowski, J. and Swinnen, J. (2014). Political reforms and public policies: Evidence from agricultural and food policy. World Bank Economic Review. 28(1), 21-47. 
Oster, E. (2012). Routes of Infection: Exports And HIV Incidence In Sub-Saharan Africa, Journal of the European Economic Association 10(5), 1025-1058.

Owen, A.L. and Wu, S. (2007). Is Trade Good for Your Health? Review of International Economics 15(4), 660-682.

Persson, T. and Tabellini, G. (2008). The Growth Effect of Democracy: Is It Heterogeneous and How Can It Be Estimated?. In Helpman, E. (eds), Institutions and Economic Performance, Harvard University Press: 544-585.

Pieters, H., Curzi, D., Olper, A. and Swinnen, J. (2016). Effect of democratic reforms on child mortality: A synthetic control analysis, The Lancet Global Health, 4, e627e632.

Pritchett, L. and Summers, L.H. (1996). Wealthier Is Healthier, Journal of Human Research 31, 841-68.

Preston, S.H. (1975). The changing relation between mortality and level of economic development, Population Studies 29, 231-48.

Ryan A.M, Burgess J.F, Dimick J.B. (2015). Why we shouldn't be indifferent to specification in difference-in-differences models. Health Services Research. 50(4), 1211-35.

Ravallion, M. (2003). The Debate on Globalization, Poverty and Inequality: Why Measurement Matters. International Affairs. 79(4), 739-753.

Ravallion, M., and Chen, S. (2007). China's (Uneven) progress against poverty. Journal of Development Economics. 82 (1), 1-42.

Sachs, J. D. and Warner, A. M. (1995). Economic reform and the process of global integration. Brookings Papers on Economic Activity 26, 1-118.

Sen, A. (1999). Wealth in Development, Bulletin of the World Health Organization, 77 (8), 619-623. 
Thomas, H. (Ed.) (2006). Trade reforms and food security. Food and Agricultural Organization, Rome.

Topalova, P. (2010). Factor Immobility and Regional Impacts of Trade Liberalization: Evidence on Poverty from India. American Economic Journal: Applied Economics 2(4), 1-41.

United Nation (2014). Levels \& Trends in Child Mortality. Report 2014.

Wade, Robert H. (2004). Is globalization reducing poverty and inequality? World Development, 32 (4), 567-589.

Wacziarg, R. and Welch, K. H. (2008). Trade liberalization and growth: New evidence, The World Bank Economic Review 22(2), 187-231.

Winters, L. A. and Martuscelli, A. (2014). Trade Liberalization and Poverty: What Have We Learned in a Decade? Annual Review of Resource Economics 6, 493-512

Winters, L. A., McCulloch, N. and McKay, A. (2004). Trade Liberalization and Poverty: The Evidence So Far. Journal of Economic Literature 42(1), 72-115.

World Bank. (2003). Mauritania - Joint staff advisory note on the second poverty reduction strategy paper. Report No. 26201-MAU, The World Bank: Washington, DC.

Zissimos, B. (2014). A Theory of Trade Policy Under Dictatorship and Democratization. University of Exeter Economics Department Discussion Paper no. 14/03. 
Table 1: Pre-Treatment Fit and Balance of Covariates in the SCM

\begin{tabular}{|c|c|c|c|c|c|c|c|c|c|c|c|c|c|c|c|c|c|c|c|}
\hline \multirow{3}{*}{ Country } & \multicolumn{9}{|c|}{ Pre-treatement fit and balance of covariates used to build the Synthetic Control } & \multirow[b]{3}{*}{ Country } & \multicolumn{9}{|c|}{ Pre-treatement fit and balance of covariates used to build the Synthetic Contro } \\
\hline & RYSPE & U5MR & & U5MR & & & & & & & & & & & & Rural & & & \\
\hline & & $\mathrm{T}_{0}-10$ & $\mathrm{~T}_{0}-5$ & $\mathrm{~T}_{0}$ & per-capita & population & growth & school & War & & & $\mathrm{T}_{0}-10$ & $\mathrm{~T}_{0}-5$ & $T_{0}$ & per-capi & $\mathrm{n}$ & growth & & War \\
\hline \multicolumn{20}{|c|}{ Group 1} \\
\hline Botswana (1979) & & 124.3 & 100.7 & 76.6 & 7.2 & 0.92 & 0.03 & 4.9 & 0.00 & Guinea-Biss. (1987) & & 229.0 & 221.1 & 211.7 & 6.9 & 0.83 & 0.02 & & 0.00 \\
\hline Synthetic Botswana & & 124.4 & 100.6 & 76.7 & 7.4 & 0.61 & 0.03 & 6.2 & 0.09 & Synthetic Guinea Biss. & 1.96 & 232.5 & 220.5 & 209.0 & 6.7 & 0.83 & 0.02 & & 0.09 \\
\hline Burundi (1999) & 025 & 164.9 & 158.8 & 151.3 & 6.1 & 0.96 & 0.02 & 6.3 & 0.00 & Madagascar (1996) & 141 & 176.8 & 153.7 & 131.8 & 6.9 & 0.82 & 0.03 & & 0.00 \\
\hline Synthetic Burundi & & 165.1 & 158.7 & 151.4 & 6.6 & 0.73 & 0.02 & 6.2 & 0.03 & Synthetic Madagascar & & 174.4 & 154.2 & 132.6 & 7.1 & 0.80 & 0.02 & & 0.00 \\
\hline Ivory Coast (1994) & 168 & 154.7 & 151.8 & 152.3 & 7.2 & 0.67 & 0.04 & 3.7 & 0.00 & Mexico (1986) & 066 & 87.5 & 70.9 & 56.2 & 8.9 & 0.39 & 0.03 & 15.69 & 0.00 \\
\hline Synthetic Ivory Coast & 1.68 & 156.6 & 152.5 & 149.0 & 6.6 & 0.71 & 0.02 & 5.5 & 0.02 & Synthetic Mexico & & 89.1 & 69.8 & 57.3 & 7.1 & 0.68 & 0.03 & 5.86 & 0.09 \\
\hline Dominican Rep. (1992) & 0.44 & 81.6 & 67.2 & 55.0 & 8.2 & 0.54 & 0.03 & 7.7 & 0.00 & Paraguay (1989) & 134 & 65.1 & 56.0 & 47.2 & 7.8 & 0.60 & 0.03 & 15.14 & 0.00 \\
\hline Synthetic Dominican Rep. & & 81.9 & 67.1 & 55.3 & 7.9 & 0.59 & 0.03 & 5.5 & 0.15 & Synthetic Paraguay & & 67.7 & 54.3 & 48.2 & 7.0 & 0.67 & 0.03 & 7.54 & 0.09 \\
\hline El Salvador (1989) & & 115.3 & 85.5 & 62.6 & 8.3 & 0.58 & 0.02 & 10.4 & 0.31 & Sri Lanka (1977) & & 76.6 & 69.1 & 59.3 & 6.7 & 0.79 & 0.02 & 9.49 & 0.06 \\
\hline Synthetic El Salvador & 1.25 & 115.8 & 84.5 & 64.2 & 8.3 & 0.57 & 0.03 & 6.4 & 0.23 & Synthetic Sri Lanka & 0.47 & 76.7 & 69.0 & 59.4 & 8.9 & 0.70 & 0.02 & 27.47 & 0.00 \\
\hline Ghana (1985) & 1.40 & 185.5 & 167.5 & 154.7 & 7.2 & 0.71 & 0.03 & 3.5 & 0.00 & Turkey (1989) & 080 & 133.0 & 103.4 & 78.1 & 8.4 & 0.58 & 0.02 & 18.12 & 0.03 \\
\hline Synthetic Ghana & & 185.7 & 167.7 & 154.8 & 7.0 & 0.71 & 0.03 & 3.9 & 0.01 & Synthetic Turkey & 0.00 & 133.5 & 102.7 & 79.5 & 7.8 & 0.60 & 0.03 & 7.23 & 0.12 \\
\hline Guatemala (1988) & 0.56 & 133.1 & 110.0 & 88.4 & 8.3 & 0.64 & 0.03 & 7.3 & 0.00 & \multicolumn{10}{|c|}{ Group 3} \\
\hline Synthetic Guatemala & & 133.4 & 109.6 & 88.9 & 7.9 & 0.61 & 0.03 & 7.9 & 0.05 & Bangladesh (1996) & 6.00 & 167.50 & 137.70 & 108.10 & 6.58 & 0.87 & 0.02 & 9.49 & 0.00 \\
\hline Honduras (1991) & 052 & 90.4 & 71.2 & 56.2 & 7.9 & 0.68 & 0.03 & 10.8 & 0.03 & Synthetic Bangladesh & & 158.19 & 137.22 & 117.50 & 7.31 & 0.77 & 0.02 & 2.78 & 0.01 \\
\hline Synthetic Honduras & 0.02 & 90.4 & 70.6 & 57.1 & 8.0 & 0.59 & 0.03 & 5.1 & 0.16 & Cameroon (1993) & 304 & 161.90 & 134.90 & 143.50 & 7.47 & 0.72 & 0.03 & 10.32 & 0.03 \\
\hline Indonesia (1970) & 0.94 & 223.1 & 194.1 & 165.2 & 6.5 & 0.84 & 0.03 & 8.8 & 0.10 & Synthetic Cameroon & & 160.65 & 138.36 & 136.36 & 6.86 & 0.69 & 0.03 & 2.77 & 0.06 \\
\hline Synthetic Indonesia & & 222.9 & 193.9 & 165.1 & 7.3 & 0.82 & 0.03 & 5.7 & 0.05 & Chile (1976) & & 104.50 & 78.50 & 57.10 & 8.32 & 0.26 & 0.02 & 24.97 & 0.00 \\
\hline Mauritania (1995) & 0.40 & 141.5 & 127.8 & 118.6 & 7.2 & 0.76 & 0.03 & 13.4 & 0.00 & Synthetic Chile & & 99.93 & 79.82 & 62.70 & 7.81 & 0.56 & 0.03 & 16.42 & 0.05 \\
\hline Synthetic Mauritania & & 141.3 & 127.7 & 118.5 & 7.0 & 0.74 & 0.03 & 11.7 & 0.04 & Colombia (1970) & 56 & 73.80 & 53.50 & 40.40 & 8.28 & 0.43 & 0.02 & 20.42 & 0.00 \\
\hline Morocco (1984) & 0.21 & 169.1 & 169.0 & 108.4 & 7.3 & 0.64 & 0.03 & 1.9 & 0.08 & Synthetic Colombia & & 78.10 & 59.60 & 45.70 & 7.71 & 0.56 & 0.03 & 3.41 & 0.12 \\
\hline Synthetic Morocco & & 139.4 & 139.3 & 108.3 & 7.3 & 0.64 & 0.03 & 2.9 & 0.10 & Egypt (1995) & 570 & 116.90 & 85.50 & 64.20 & 7.30 & 0.57 & 0.02 & 3.54 & 0.06 \\
\hline $\begin{array}{l}\text { Nicaragua (1991) } \\
\end{array}$ & 072 & 100.6 & 77.5 & 63.3 & 8.1 & 0.52 & 0.03 & 9.1 & 0.26 & Synthetic Control & & 108.82 & 84.87 & 73.49 & 7.95 & 0.64 & 0.03 & 2.47 & 0.05 \\
\hline Synthetic Nicaragua & 72 & 100.7 & 77.5 & 63.4 & 8.2 & 0.54 & 0.03 & 6.4 & 0.28 & Gambia (1985) & 2.50 & 268.90 & 237.00 & 203.30 & 7.12 & 0.78 & 0.03 & 0.54 & 0.00 \\
\hline Perù (1991) & & 120.3 & 120.3 & 74.9 & 8.5 & 0.40 & 0.03 & 14.2 & 0.26 & Synthetic Gambia & & 267.69 & 234.95 & 206.42 & 6.13 & 0.95 & 0.02 & 4.61 & 0 \\
\hline Synthetic Perù & 1.14 & 97.7 & 95.7 & 77.8 & 8.1 & 0.58 & 0.03 & 8.2 & 0.19 & Guinea (1986) & 23.20 & 304.40 & 282.10 & 259.60 & 6.67 & 0.82 & 0.01 & & 0.00 \\
\hline South Africa (1991) & 0.22 & 87.0 & 69.8 & 59.3 & 8.6 & 0.52 & 0.02 & 9.0 & 0.26 & Synthetic Guinea & & 292.60 & 250.40 & 252.70 & 6.27 & 0.93 & 0.03 & & 0.00 \\
\hline Synthetic South Africa & & 87.0 & 69.6 & 59.4 & 8.5 & 0.52 & 0.03 & 6.7 & 0.27 & Guyana (1988) & 3.25 & 71.80 & 68.70 & 63.10 & 7.93 & 0.70 & 0.01 & 41.30 & 0.00 \\
\hline Tanzania (1995) & 0.61 & 176.4 & 166.2 & 159.6 & 6.4 & 0.87 & 0.03 & 12.8 & 0.00 & Synthetic Guyana & & 78.50 & 64.90 & 63.61 & 6.15 & 0.80 & 0.02 & 11.60 & 0.07 \\
\hline Synthetic Tanzania & & 176.3 & 166.0 & 159.4 & 7.1 & 0.70 & 0.03 & 8.0 & 0.00 & Kenya (1993) & 4.55 & 98.70 & 95.40 & 106.00 & 6.99 & 0.87 & 0.04 & 16.32 & 0.00 \\
\hline Tunisia (1989) & 0.65 & 99.9 & 72.3 & 53.9 & 8.0 & 0.53 & 0.02 & 5.9 & 0.03 & Synthetic Kenya & & 101.58 & 98.54 & 95.84 & 6.42 & 0.76 & 0.02 & 9.76 & 0.04 \\
\hline Synthetic Tunisia & & 100.0 & 72.1 & 54.3 & 7.7 & 0.58 & 0.03 & 4.7 & 0.08 & $\begin{array}{l}\text { Mozambique (1995) } \\
\end{array}$ & 2.62 & 246.50 & 232.60 & 208.40 & 5.86 & 0.88 & 0.02 & 5.32 & 0.37 \\
\hline \multicolumn{10}{|c|}{$\begin{array}{l}\text { Group } 2 \\
\end{array}$} & Synthetic Mozambique & & 243.02 & 233.94 & 206.69 & 6.35 & 0.89 & 0.03 & 8.22 & 0.00 \\
\hline Benin (1990) & & 213.6 & 200.00 & 180.70 & 6.76 & 0.78 & 0.02 & 2.51 & 0.00 & Nepal (1991) & 3.07 & 202.90 & 170.00 & 135.00 & 6.39 & 0.95 & 0.02 & 0.46 & 0 \\
\hline Synthetic Benin & 1.02 & 215.2 & 198.68 & 181.85 & 6. & 0.79 & 0.03 & 8.39 & 0.00 & Synthetic Nepal & & 199.96 & 167.15 & 141.57 & 7.12 & 0.68 & 0.03 & 12.68 & 0 \\
\hline Brazil (1991) & & 90.3 & 72.30 & 59.20 & 8.46 & 0.39 & 0.02 & 15.51 & 0.00 & Philippines (1988) & 3.08 & 82.50 & 78.20 & 65.60 & 7.58 & 0.64 & 0.03 & 20.98 & 0.29 \\
\hline Synthetic Brazil & 0.11 & 90.5 & 71.87 & 59.62 & 8.09 & 0.51 & 0.03 & 5.59 & 0.32 & Synthetic Philippines & & 88.54 & 74.79 & 66.83 & 7.81 & 0.60 & 0.03 & 3.98 & 0.36 \\
\hline Burkina Faso (1998) & & 205.0 & 201.60 & 191.40 & 6.37 & 0.91 & 0.02 & & 0.00 & Uganda (1988) & 6.27 & 206.70 & 199.40 & 180.40 & 6.50 & 0.93 & 0.03 & 5.22 & 0.25 \\
\hline Synthetic Burki & 1.14 & 205.2 & 201.79 & 191.59 & 6.98 & 0.74 & 0.03 & & 0.10 & Synthetic Uganda & & 213.48 & 193.99 & 183.24 & 6.78 & 0.74 & 0.03 & 6.42 & 0.00 \\
\hline Cape Verde (1991) & & 89.0 & 71.30 & 59.10 & 6.97 & 0.76 & 0.02 & & 0.00 & Zambia (1993) & 12.42 & 164.80 & 186.80 & 192.40 & 7.15 & 0.66 & 0.03 & 8.92 & 0.00 \\
\hline Synthetic Cape Verde & 0.02 & 89.2 & 70.81 & 59.93 & 7.66 & 0.65 & 0.03 & & 0.20 & Synthetic Zambia & & 186.04 & 183.98 & 177.02 & 6.69 & 0.72 & 0.02 & 4.67 & 0.00 \\
\hline Ethiopia (1996) & & 217.5 & 199.80 & 167.70 & 6.06 & 0.90 & 0.02 & & 0.44 & & & & & & & & & & \\
\hline Synthetic Ethiopia & & 215.9 & 198.72 & 172.07 & 6.66 & 0.86 & 03 & & & & & & & & & & & & \\
\hline
\end{tabular}

Notes: Table shows the balance of covariates between treated units and the synthetic controls. The overall fit is defined by the RMSPE. See text for details. 
Table 2: Summary of SCM Results for Group 1 and Group 2 Countries

\begin{tabular}{|c|c|c|c|c|c|c|c|c|c|}
\hline \multirow{2}{*}{$\#$} & \multirow{2}{*}{ Country } & \multirow{2}{*}{ Group } & \multirow{2}{*}{$\begin{array}{c}\text { Year of } \\
\text { Reform } \\
\left(T_{0}\right) \\
\end{array}$} & \multicolumn{3}{|c|}{ Under 5 Mortality Rate } & \multicolumn{2}{|c|}{ Average Treatment Effect } & \multirow{2}{*}{ p-value } \\
\hline & & & & $T_{0}$ & $T+5$ & $T+10$ & $T+5(\%)$ & $T+10(\%)$ & \\
\hline 1 & Perù & Group 1 & 1991 & 74.90 & 53.59 & 37.00 & $-26.1 \%$ & $-34.5 \%$ & 0.00 \\
\hline 2 & Turkey & Group 2 & 1989 & 78.10 & 58.00 & 40.59 & $-18.6 \%$ & $-33.9 \%$ & 0.01 \\
\hline 3 & Sri Lanka & Group 2 & 1977 & 59.30 & 42.10 & 24.40 & $-11.7 \%$ & $-28.1 \%$ & 0.07 \\
\hline 4 & Brazil & Group 2 & 1991 & 59.20 & 44.20 & 30.79 & $-17.0 \%$ & $-27.3 \%$ & 0.02 \\
\hline 5 & Guatemala & Group 1 & 1988 & 88.40 & 69.50 & 55.09 & $-12.7 \%$ & $-25.6 \%$ & 0.06 \\
\hline 6 & Tanzania & Group 1 & 1995 & 159.60 & 131.50 & 90.10 & $-11.4 \%$ & $-23.8 \%$ & 0.01 \\
\hline 7 & El Salvador & Group 1 & 1989 & 62.60 & 46.90 & 33.90 & $-11.8 \%$ & $-20.0 \%$ & 0.02 \\
\hline 8 & Mexico & Group 2 & 1986 & 56.20 & 43.80 & 32.70 & $-12.2 \%$ & $-18.5 \%$ & 0.11 \\
\hline 9 & Ghana & Group 1 & 1985 & 154.70 & 128.10 & 113.30 & $-11.6 \%$ & $-18.0 \%$ & 0.11 \\
\hline 10 & Tunisia & Group 1 & 1989 & 53.90 & 41.40 & 31.50 & $-10.5 \%$ & $-17.5 \%$ & 0.12 \\
\hline 11 & Nicaragua & Group 1 & 1991 & 63.30 & 49.70 & 38.10 & $-12.4 \%$ & $-17.4 \%$ & 0.01 \\
\hline 12 & Indonesia & Group 1 & 1970 & 165.20 & 139.89 & 120.00 & $-7.1 \%$ & $-15.2 \%$ & 0.07 \\
\hline 13 & Madagascar & Group 2 & 1996 & 131.80 & 102.60 & 76.09 & $-6.0 \%$ & $-11.2 \%$ & 0.18 \\
\hline 14 & Burkina Faso & Group 2 & 1998 & 191.40 & 174.00 & 131.60 & $1.9 \%$ & $-8.5 \%$ & 0.39 \\
\hline 15 & Morocco & Group 1 & 1984 & 108.40 & 83.80 & 66.40 & $-3.5 \%$ & $-8.0 \%$ & 0.37 \\
\hline 16 & Cape Verde & Group 2 & 1991 & 59.10 & 47.50 & 35.50 & $-3.5 \%$ & $-5.5 \%$ & 0.16 \\
\hline 17 & Honduras & Group 1 & 1991 & 56.20 & 45.09 & 36.29 & $-4.4 \%$ & $-4.8 \%$ & 0.21 \\
\hline 18 & Burundi & Group 1 & 1999 & 151.30 & 138.50 & 115.80 & $-0.7 \%$ & $-4.1 \%$ & 0.09 \\
\hline 19 & Ivory Coast & Group 1 & 1994 & 152.30 & 147.40 & 134.50 & $1.4 \%$ & $-2.9 \%$ & 0.39 \\
\hline 20 & Guinea-Bissau & Group 2 & 1987 & 211.70 & 201.60 & 185.00 & $1.4 \%$ & $-2.9 \%$ & 0.54 \\
\hline 21 & Benin & Group 2 & 1990 & 180.70 & 158.20 & 147.39 & $-6.9 \%$ & $-2.7 \%$ & 0.17 \\
\hline 22 & Ethiopia & Group 2 & 1996 & 167.70 & 139.70 & 101.90 & $1.0 \%$ & $-0.1 \%$ & 0.17 \\
\hline 23 & Paraguay & Group 2 & 1989 & 47.20 & 39.59 & 33.79 & $-4.3 \%$ & $0.3 \%$ & 0.25 \\
\hline 24 & Dominican Republic & Group 1 & 1992 & 55.00 & 44.70 & 37.29 & $-0.9 \%$ & $4.7 \%$ & 0.26 \\
\hline 25 & Botswana & Group 1 & 1979 & 76.60 & 58.29 & 48.29 & $4.9 \%$ & $7.3 \%$ & 0.34 \\
\hline 26 & Mauritania & Group 1 & 1995 & 118.60 & 110.50 & 101.70 & $6.1 \%$ & $24.1 \%$ & 0.12 \\
\hline 27 & South Africa & Group 1 & 1991 & 59.30 & 61.70 & 76.70 & $15.8 \%$ & $52.0 \%$ & 0.09 \\
\hline
\end{tabular}

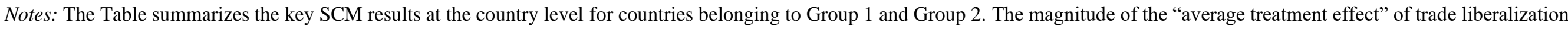
on the U5MR is measured as the \% deviation of the treated country in comparison to the (counterfactual) synthetic control. See Text. 
Table 3: Summary of Significant Effects

\begin{tabular}{|l|c|c|}
\hline$p<0.10$ & Group 1 & Group 1+2 \\
\hline Significant Reduction & 7 & 10 \\
Not significant & 8 & 16 \\
Significant Increase & 1 & 1 \\
\hline$p<0.15$ & & 13 \\
\hline Significant Reduction & 9 & 12 \\
Not significant & 5 & 2 \\
Significant Increase & 2 & \\
\hline
\end{tabular}

Notes: Number of significant cases for $p$-value cut-offs at 0.10 and at 0.15 . See Text.

Table 4: Average HIV Prevalence (\% of population age 15-49) in the Post-treatment Period by Group of Countries

\begin{tabular}{|l|cc|cc|}
\hline & \multicolumn{2}{|c|}{ Group 1 } & \multicolumn{2}{c|}{ Group 1+2 } \\
\cline { 2 - 5 } & HIV prevalence & $\begin{array}{c}\text { Number of } \\
\text { countries } \\
\text { Avg } \% \text { of pop. } \\
\text { age 15-49 }\end{array}$ & $\begin{array}{c}\text { HIV prevalence } \\
\text { Avg \% of pop. } \\
\text { age 15-49 }\end{array}$ & $\begin{array}{c}\text { Number of } \\
\text { countries }\end{array}$ \\
\hline Significant Reduction & $1,9 \%$ & 6 & $1,9 \%$ & 6 \\
Not significant & $1,7 \%$ & 7 & $1,3 \%$ & 15 \\
Significant Increase & $9,7 \%$ & 1 & $9,7 \%$ & 1 \\
\hline
\end{tabular}

Notes: See Text. 


\section{Figure 1: Difference between Treated and Control and Placebo-in-Space Tests for Group 1 Countries}

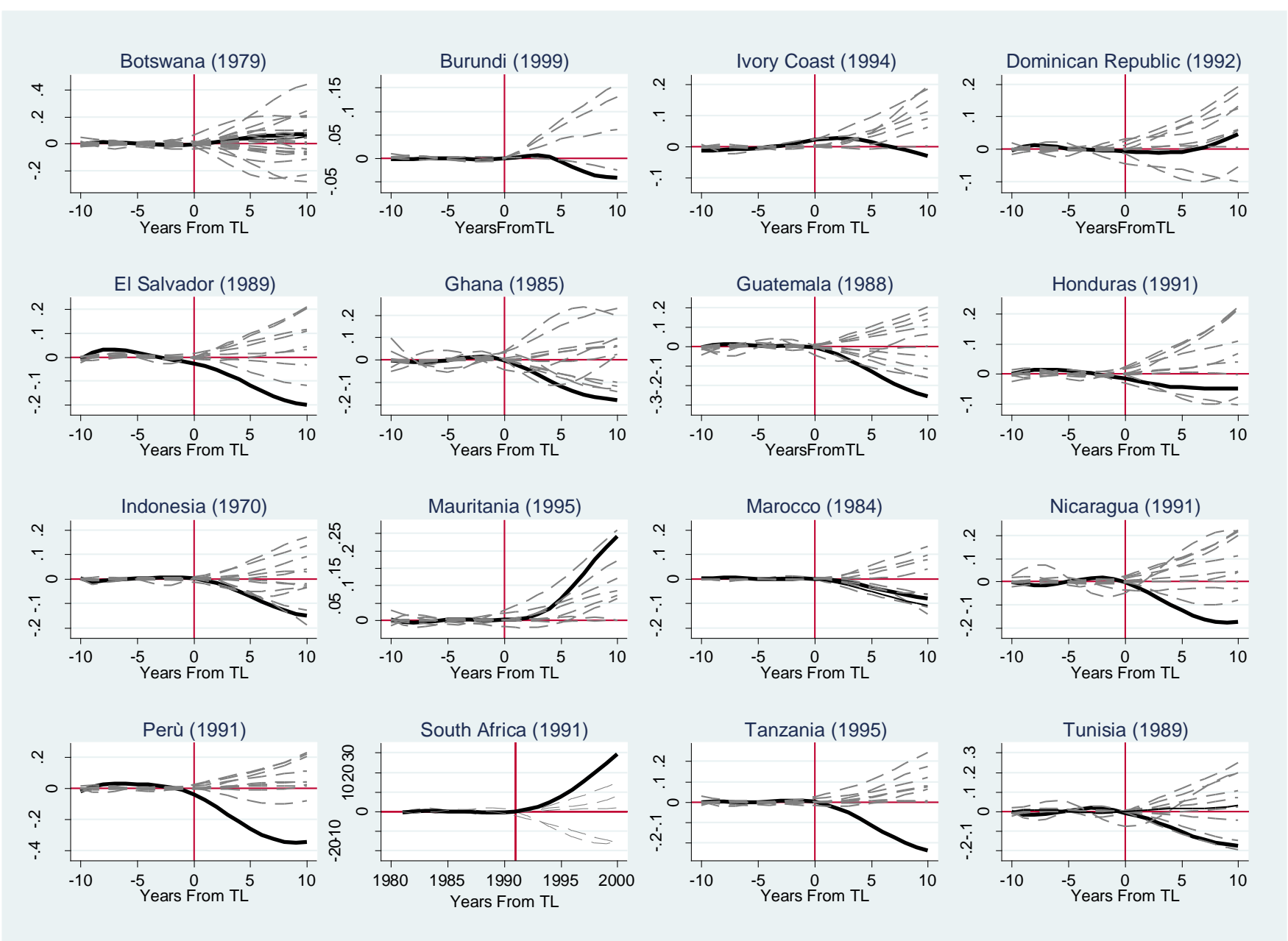

Notes: The bold line reports the outcome difference between each treated unit and the synthetic control; instead the grey dash lines report the outcome differences between each (fake) treated country (from the donor pool) and their synthetic control in the placebo tests. 
Figure 2: Difference between Treated and Control and Placebo-in-Space Tests for Group 2 Countries
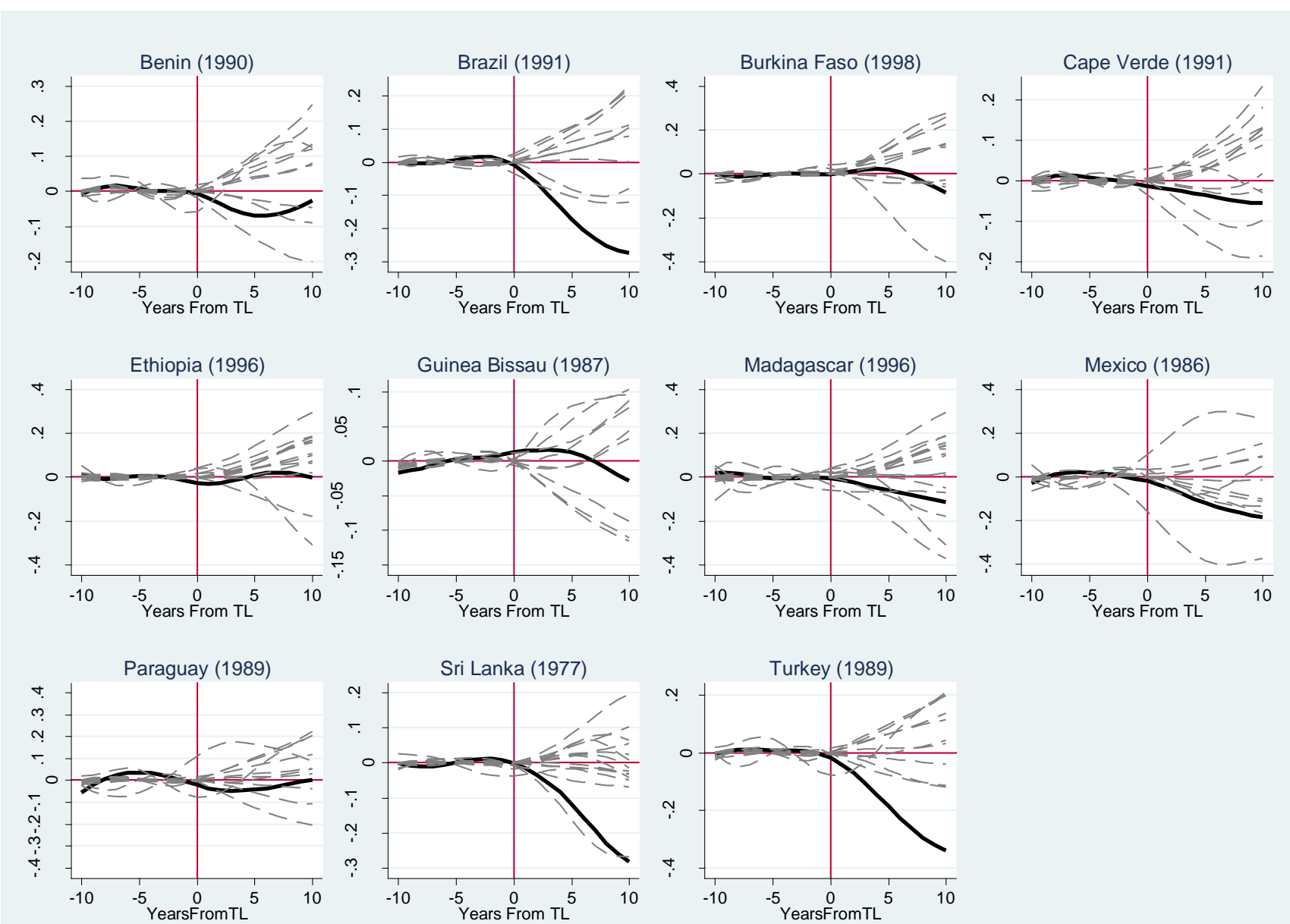

Notes: The bold line reports the outcome difference between each treated unit and the synthetic control; instead the grey dash lines report the outcome differences between each (fake) treated country (from the donor pool) and their synthetic control in the placebo tests. 
Figure 3: Placebo In-Time Tests

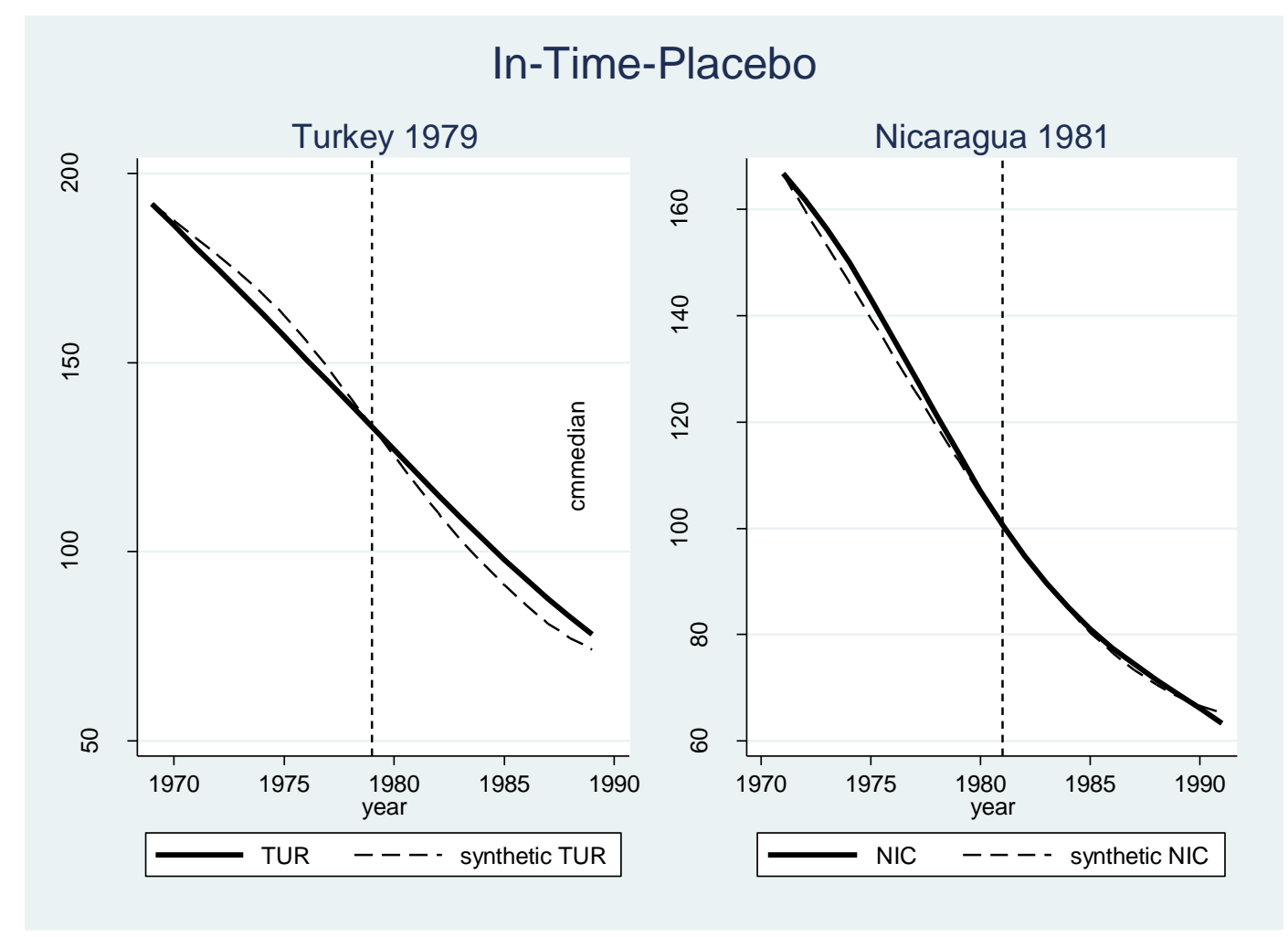

Notes: Figure presents the results for the in-time Placebo tests for Turkey and Nicaragua, where the treatment has been assigned 10 years in advance with respect to the real one. The bold line and the dashed line represent the evolution of Under 5 mortality rate for the treated countries and synthetic controls, respectively. 
Figure 4: Average Treatment Effect in Group 1 and Group 1+2

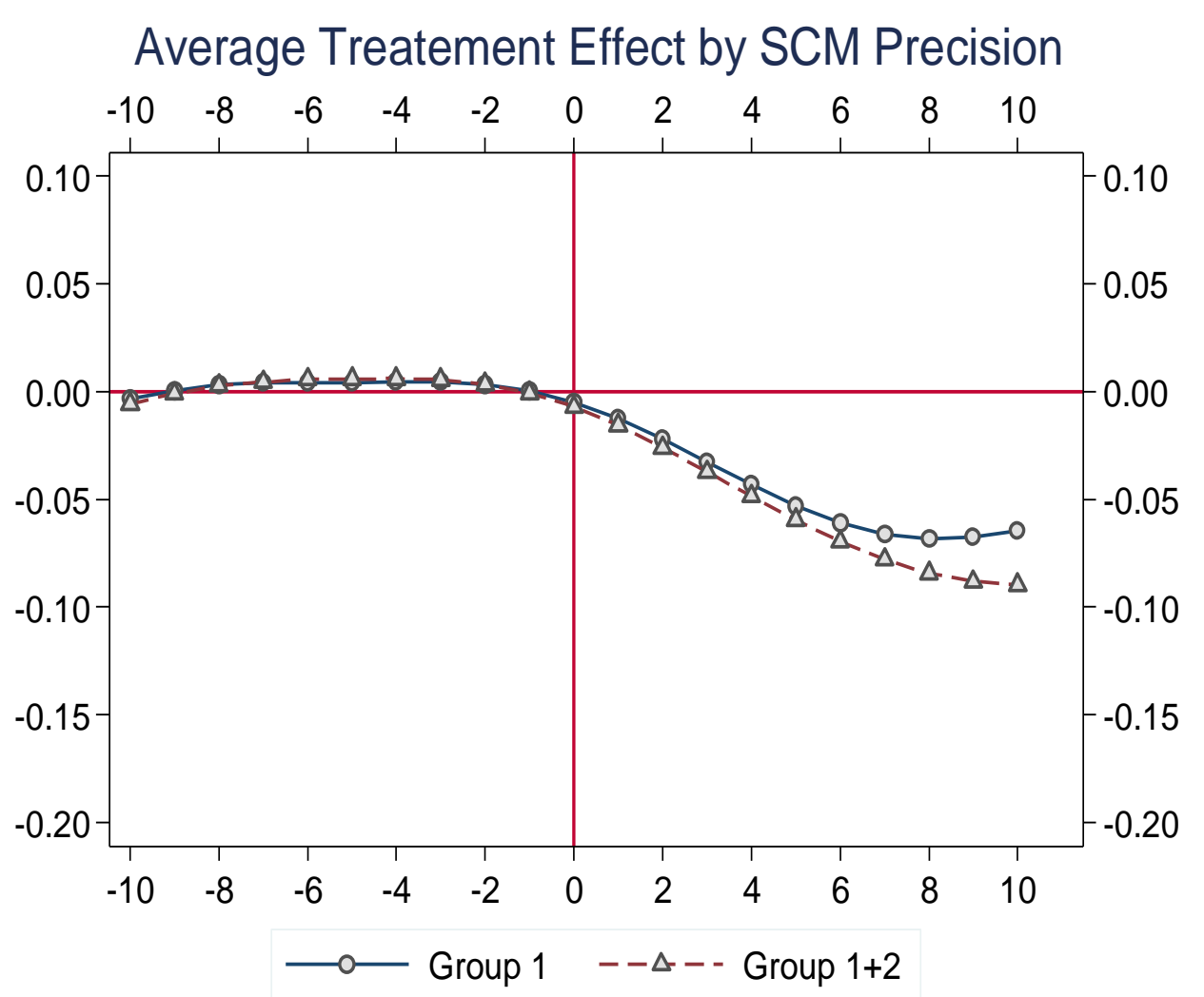

Notes: The figure reports the dynamic treatment effects aggregated across all the countries belonging to Group 1 and Group $1+2$ selected using equation (5); the corresponding $p$-value, computed as discussed in section 2.2 , is reported in the text (in bracket). Before aggregation, the individual country estimates are normalized by setting the child mortality of the treated country equal to 1 in the year of trade reform, $T_{0}$. 
Figure 5. Average Treatment Effect in Different Political Regimes

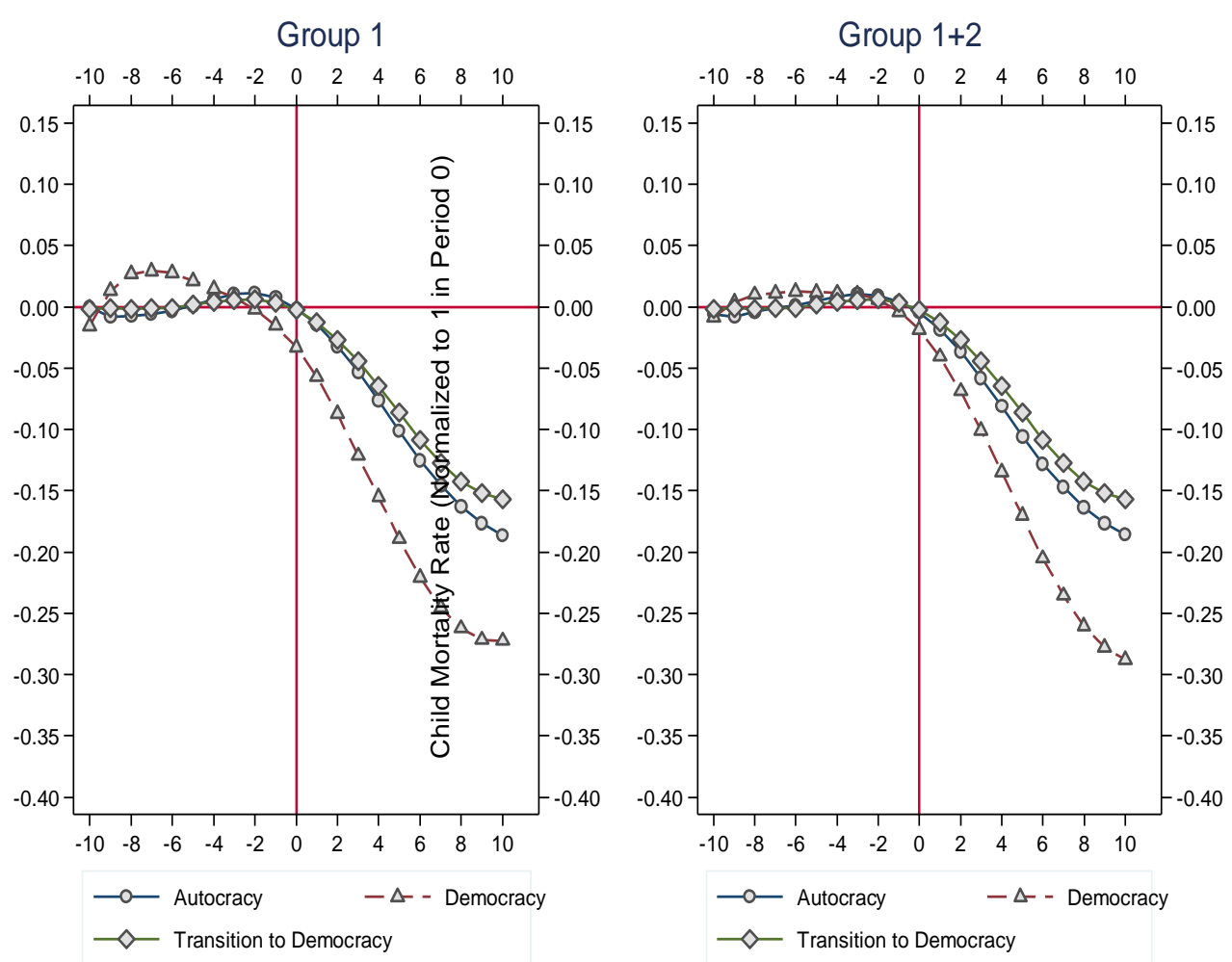

Notes: The figure reports the average treatment effect of trade reforms aggregated across different political regimes using equation (5). "Democracy" includes El Salvador and Perù in Group 1; and Brazil, Sri Lanka and Turkey in Group 2. "Autocracy" includes Ghana, Indonesia, Tanzania and Tunisia in Group 1; and Mexico in Group 2. "Transition to Democracy" includes Burundi; Guatemala; and Nicaragua, all in Group 1. 
Figure 6: HIV Prevalence (\% of population age 15-49) and Under-five Mortality Rate

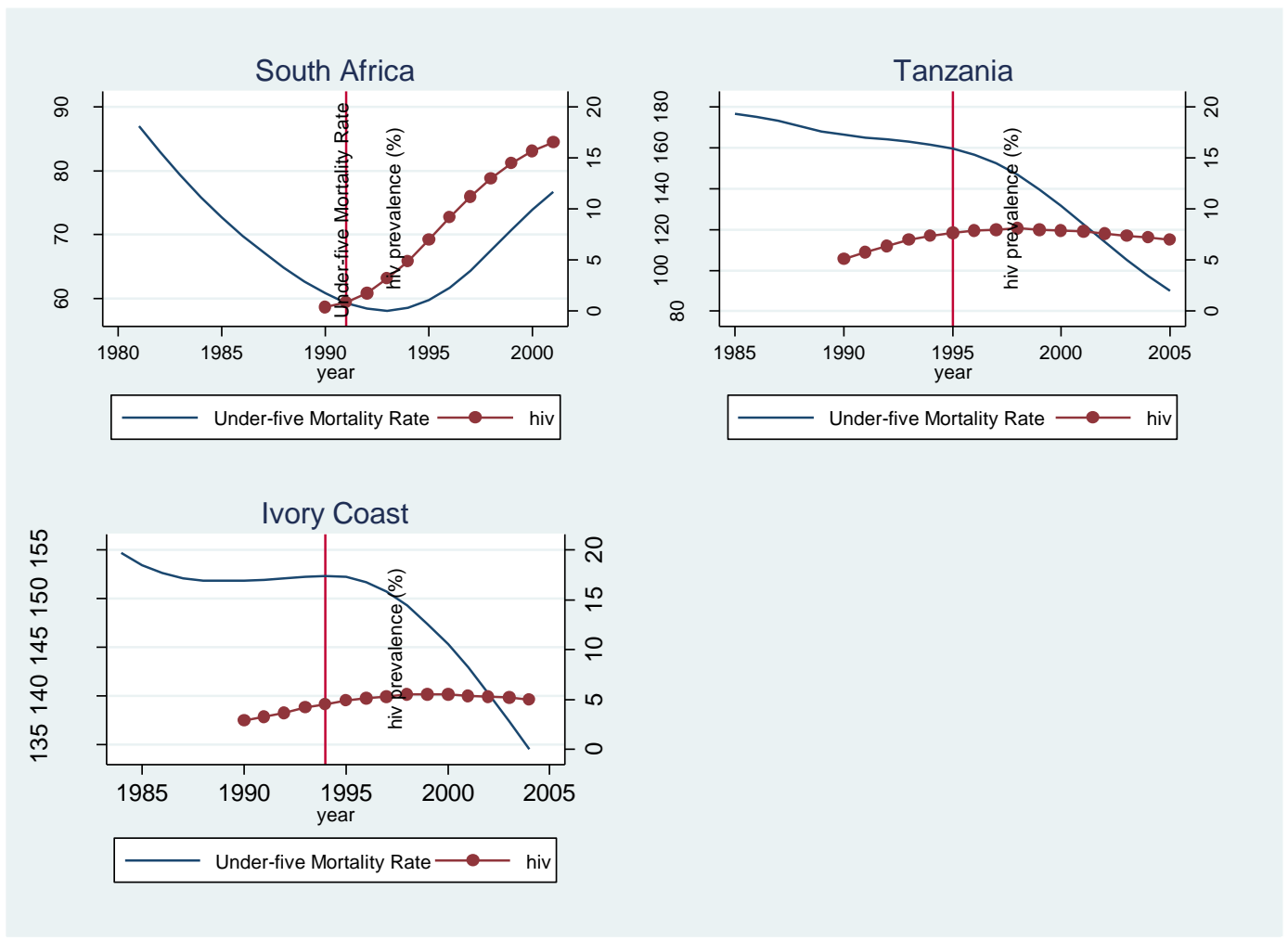

Notes: The vertical line is the year of trade liberalization. See Text. 


\section{Figure 7. Average Treatment Effect in High and Low Income Groups}
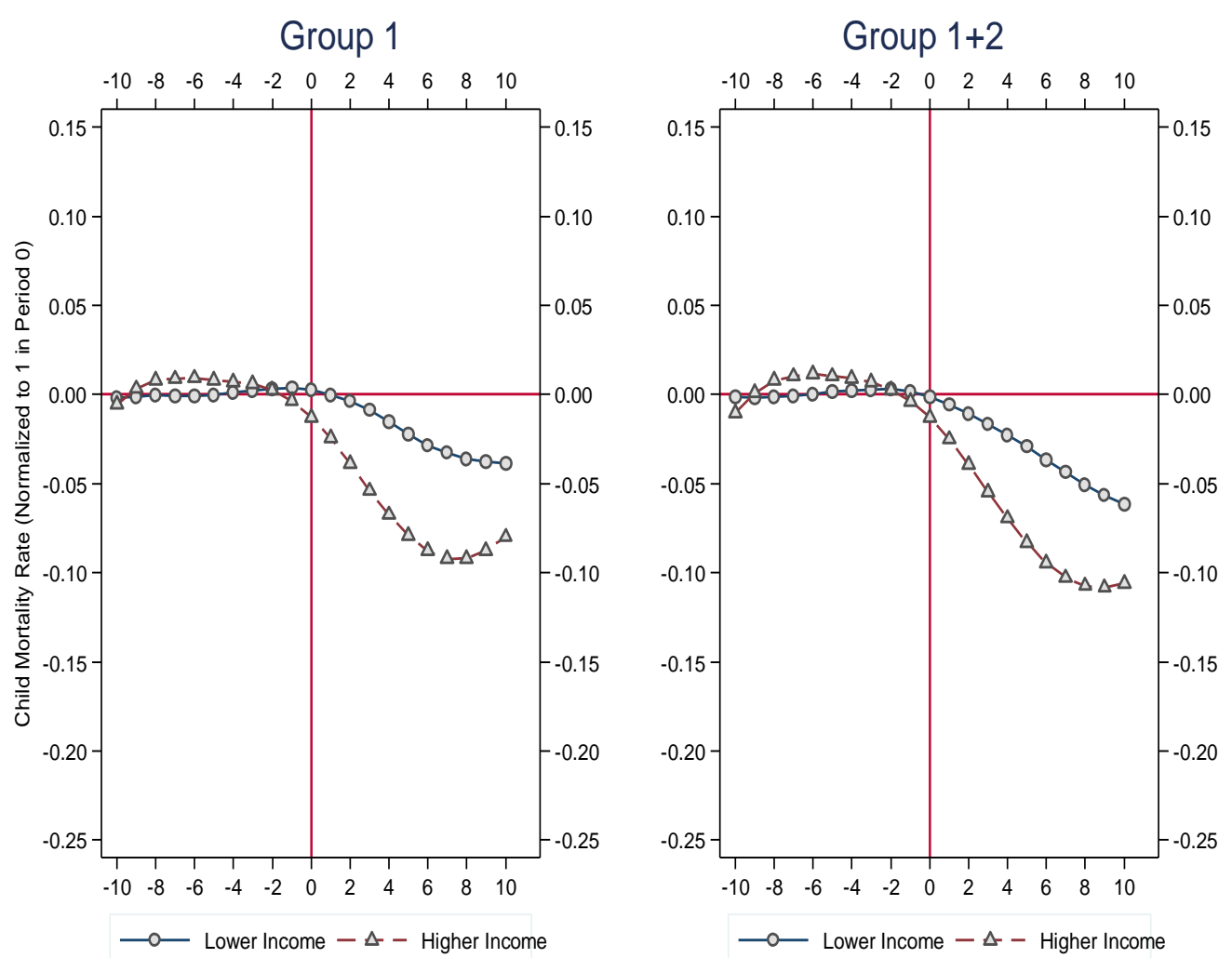

Notes: The figure reports the dynamic treatment effects aggregated by level of income (High vs. Low), using equation (5). "Lower Income" includes Burundi, Ghana, Indonesia, Ivory Coast, Mauritania and Tanzania in Group 1; and Benin, Burkina Faso, Cape Verde, Ethiopia, Guinea-Bissau-Madagascar and Sri Lanka in Group 2. "Higher 
Income" includes Botswana, Dominican Republic, El Salvador, Guatemala, Honduras, Morocco, Nicaragua, Perù, South Africa and Tunisia in Group 1; and Brazil, Mexico,

Paraguay and Turkey in Group 2. 
Figure 8. Average Treatment Effect and Agricultural Policy Change (High and Low Growth in Nominal Rate of Assistance to Agriculture (NRA))

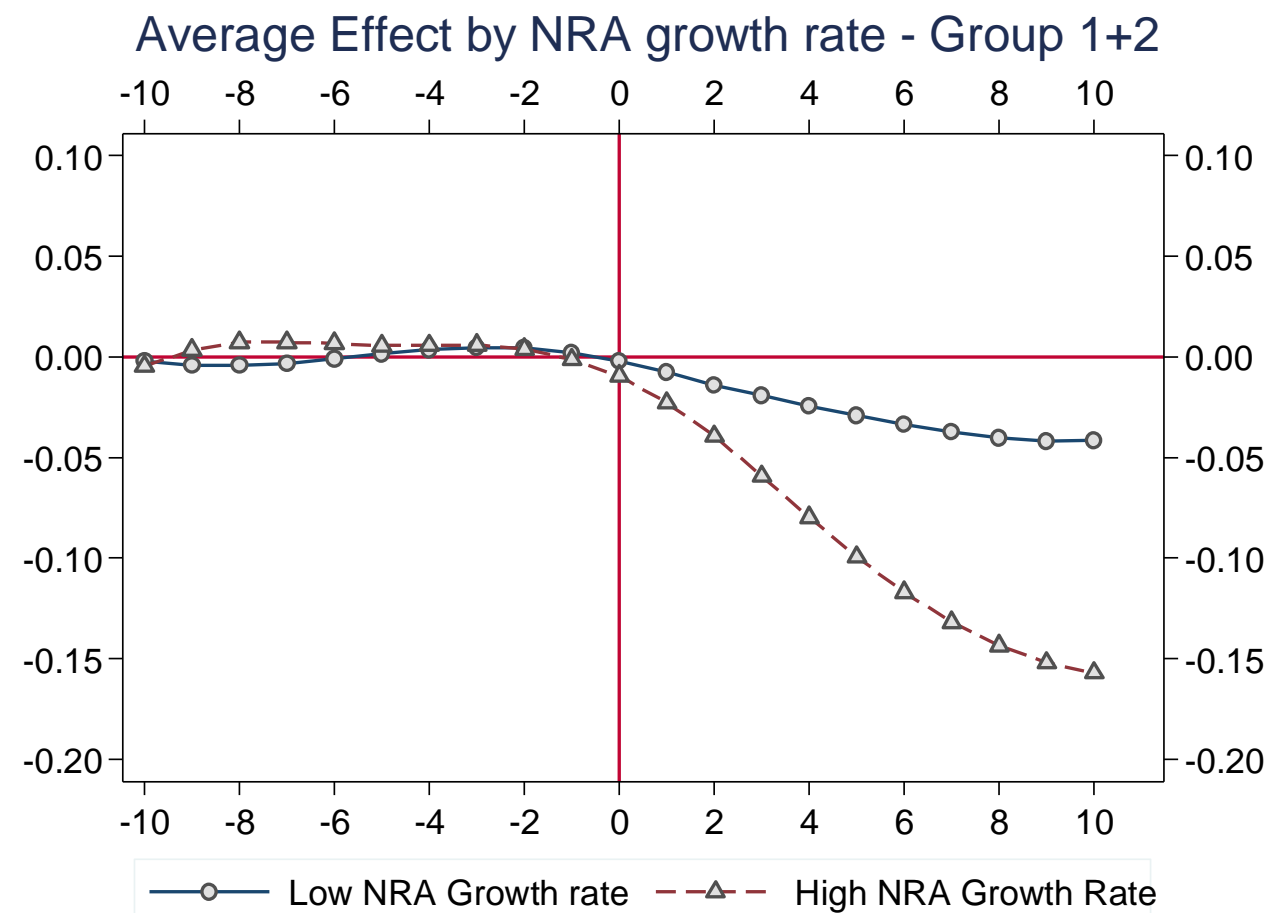

Notes: The figure reports the dynamic treatment effects aggregated across NRA growth rate groups (High vs. Low). Countries in the Low-NRA growth rate group are: Benin, Burkina Faso, Ivory Coast, Ethiopia, Nicaragua, Sri Lanka, South Africa and Tanzania. Countries in the High-NRA growth rate group are: Brazil, Dominican Republic, Ghana, Indonesia, Madagascar, Mexico and Turkey. See text for definition of low versus high NRA growth. 


\section{Appendix}

\section{Table A1. Country Weights in the Synthetic Controls}

\begin{tabular}{|l|}
\hline Group 1 Countries \\
Synthetic Botswana: Argentina (0.001); China (0.158); Algeria (0.12); Panama (0.092); Syria (0.629). Synthetic Burundi: Central African \\
Republic (0.594); China (0.134); Rep. Dem. Congo (0.155); Malawi (0.117). Synthetic Ivory Coast: Central African Republic (0.676); Rep. \\
Dem. Congo (0.165); China (0.165). Synthetic Dominican Republic: China (0.033); Iran (0.311); Malawi (0.077); Syria (0.58). Synthetic El \\
Salvador: Algeria (0.038); Iran (0.57); Senegal (0.122); Syria (0.27). Synthetic Ghana: Algeria (0.016); Central African Republic (0.588); \\
Panama (0.006); Papua New Guinea (0.027); Senegal (0.083); Syria (0.096); Togo (0.185). Synthetic Guatemala: Algeria (0.027); Gabon \\
(0.221); Haiti (0.025); Senegal (0.298); Syria (0.429). Synthetic Honduras: Haiti (0.095); Iran (0.349); Papua Nuova Guinea (0.055); Senegal \\
(0.022); Syria (0.478). Synthetic Indonesia: Cameroon (0.127); India (0.049); Philippines (0.066); Papua Nuova Guinea $(0.117) ;$ Trinidad and \\
Tobago (0.07); Tunisia (0.232); Uganda (0.338). Synthetic Mauritania: China (0.3); Gabon (0.061); Iran $(0.093) ;$ Malawi $(0.228) ;$ Senegal \\
(0.317). Synthetic Morocco: Algeria (0.038); Burundi (0.046); Central African Republic (0.112); China (0.008); Egypt $(0.396) ;$ Iraq (0.058); \\
Papua Nuova Guinea (0.117); Syria (0.225). Synthetic Nicaragua: Algeria (0.034); China (0.011); Gabon (0.009); Iran (0.366); Iraq (0.224); \\
Senegal (0.155); Syria (0.202). Synthetic Perù: Iran (0.465); Iraq (0.04); Senegal (0.316); Syria (0.179). Synthetic South Africa: China \\
(0.016); Gabon (0.219); Haiti (0.016); Iran (0.305); Iraq (0.243); Syria (0.2). Synthetic Tanzania: Central African Republic $(0.495) ;$ Gabon \\
(0.141); Malawi (0.164); Senegal (0.199). Synthetic Tunisia: Algeria (0.161); China (0.036); Senegal (0.116); Syria (0.687).
\end{tabular}




\section{Group 2 Countries}

Synthetic Benin: Central African Republic (0.144); Malawi (0.383); Papua Nuova Guinea (0.063); Senegal (0.41). Synthetic Brazil: Iran (0.237); Iraq (0.353); Senegal (0.132); Syria (0.277). Synthetic Burkina Faso: Central African Republic (0.106); Rep. Dem. Congo (0.101); Malawi (0.018); Nigeria (0.621); Chad (0.155). Synthetic Cape Verde: China (0.301); India(0.124); Iran (0.453); Syria (0.122). Synthetic Ethiopia: Haiti (0.401); Malawi (0.599). Synthetic Guinea Bissau: Central African Republic (0.171); Chad (0.829). Synthetic Madagascar: Haiti (0.854); Malawi (0.146). Synthetic Mexico: Burundi (0.051); China (0.288); Papua Nuova Guinea (0.061); Syria (0. 6). Synthetic Paraguay: Central African Republic (0.018); China (0.44); Syria (0.542). Synthetic Sri Lanka: Algeria (0.019); Nicaragua (0.098); Paraguay (0.125); Trinidad and Tobago (0.585); Venezuela (0.173). Synthetic Turkey: Algeria (0.092); China (0.027); Iran (0.216); Senegal (0.322); Syria (0.344). 
Table A2: Summary of the SCM Results Accounting for Possible SUTVA Violation

\begin{tabular}{|c|c|c|c|c|c|c|c|c|c|c|c|}
\hline \multirow{3}{*}{$\#$} & \multirow{3}{*}{ Country } & \multirow{3}{*}{ Group } & \multirow{3}{*}{$\begin{array}{c}\text { Year of } \\
\text { Reform } \\
\left(T_{0}\right)\end{array}$} & \multicolumn{4}{|c|}{ Baseline Model } & \multicolumn{4}{|c|}{ Considering SUTVA } \\
\hline & & & & \multicolumn{2}{|c|}{ Average Treatment Effect } & \multirow{2}{*}{ RMSPE } & \multirow{2}{*}{ p-value } & \multicolumn{2}{|c|}{ Average Treatment Effect } & \multirow{2}{*}{ RMSPE } & \multirow{2}{*}{ p-value } \\
\hline & & & & $T+5$ & $T+10$ & & & $T+5(\%)$ & $T+10(\%)$ & & \\
\hline$\overline{c 1}$ & $\begin{array}{l}\text { Turkey } \\
\end{array}$ & Second & 1989 & $18.58 \%$ & $33.95 \%$ & 0.80 & $\overline{0.01}$ & $-23.14 \%$ & $-40.76 \%$ & $\overline{c 1.63}$ & $\overline{0.01}$ \\
\hline 2 & Perù & First & 1991 & $26.09 \%$ & $34.46 \%$ & 1.74 & 0.00 & $-26.09 \%$ & $-34.46 \%$ & 1.74 & 0.00 \\
\hline 3 & Tanzania & First & 1995 & $11.35 \%$ & $23.80 \%$ & 0.61 & 0.01 & $-12.95 \%$ & $-33.88 \%$ & 1.83 & 0.04 \\
\hline 4 & Sri Lanka & Second & 1977 & $11.65 \%$ & $28.11 \%$ & 0.47 & 0.07 & $-11.65 \%$ & $-28.11 \%$ & 0.47 & 0.07 \\
\hline 5 & Brazil & Second & 1991 & $17.05 \%$ & $27.27 \%$ & 0.51 & 0.02 & $-17.05 \%$ & $-27.27 \%$ & 0.51 & 0.02 \\
\hline 6 & Guatemala & First & 1988 & $12.69 \%$ & $25.64 \%$ & 0.56 & 0.06 & $-12.69 \%$ & $-25.64 \%$ & 0.56 & 0.06 \\
\hline 7 & El Salvador & First & 1989 & $11.76 \%$ & $19.98 \%$ & 1.25 & 0.02 & $-11.76 \%$ & $-19.98 \%$ & 1.25 & 0.02 \\
\hline 8 & Indonesia & First & 1970 & $7.10 \%$ & $15.20 \%$ & 0.94 & 0.07 & $-8.72 \%$ & $-19.03 \%$ & 1.06 & 0.04 \\
\hline 9 & Mexico & Second & 1986 & $12.15 \%$ & $18.50 \%$ & 0.66 & 0.11 & $-12.15 \%$ & $-18.50 \%$ & 0.66 & 0.11 \\
\hline 10 & Nicaragua & First & 1991 & $12.39 \%$ & $17.38 \%$ & 0.72 & 0.01 & $-12.39 \%$ & $-17.38 \%$ & 0.72 & 0.01 \\
\hline 11 & Ghana & First & 1985 & $11.60 \%$ & $17.97 \%$ & 1.40 & 0.11 & $-6.73 \%$ & $-12.00 \%$ & 1.37 & 0.13 \\
\hline 12 & Madagascar & Second & 1996 & $6.04 \%$ & $11.23 \%$ & 1.41 & 0.18 & $-6.04 \%$ & $-11.23 \%$ & 1.41 & 0.18 \\
\hline 13 & Burkina Faso & Second & 1998 & $-1.90 \%$ & $8.47 \%$ & 1.14 & 0.39 & $1.90 \%$ & $-8.47 \%$ & 1.14 & 0.39 \\
\hline 14 & Morocco & First & 1984 & $3.46 \%$ & $8.01 \%$ & 0.21 & 0.37 & $-3.22 \%$ & $-7.91 \%$ & 0.20 & 0.25 \\
\hline 15 & Tunisia & First & 1989 & $10.54 \%$ & $17.55 \%$ & 0.65 & 0.12 & $-4.51 \%$ & $-6.97 \%$ & 0.47 & 0.10 \\
\hline 16 & Burundi & First & 1999 & $0.66 \%$ & $4.08 \%$ & 0.25 & 0.10 & $-0.96 \%$ & $-5.70 \%$ & 0.30 & 0.10 \\
\hline 17 & Cape Verde & Second & 1991 & $3.45 \%$ & $5.52 \%$ & 0.52 & 0.16 & $-3.45 \%$ & $-5.52 \%$ & 0.52 & 0.16 \\
\hline 18 & Honduras & First & 1991 & $4.40 \%$ & $4.80 \%$ & 0.52 & 0.21 & $-4.40 \%$ & $-4.80 \%$ & 0.52 & 0.21 \\
\hline 19 & Ivory Coast & First & 1994 & $-1.39 \%$ & $2.94 \%$ & 1.68 & 0.39 & $1.39 \%$ & $-2.94 \%$ & 1.68 & 0.39 \\
\hline 20 & Guinea-Bissau & Second & 1987 & $-1.35 \%$ & $2.86 \%$ & 1.96 & 0.54 & $1.35 \%$ & $-2.86 \%$ & 1.96 & 0.54 \\
\hline 21 & Benin & Second & 1990 & $6.88 \%$ & $2.66 \%$ & 1.52 & 0.17 & $-6.88 \%$ & $-2.66 \%$ & 1.52 & 0.17 \\
\hline 22 & Ethiopia & Second & 1996 & $-0.98 \%$ & $0.09 \%$ & 1.76 & 0.17 & $0.98 \%$ & $-0.09 \%$ & 1.76 & 0.17 \\
\hline 23 & Paraguay & Second & 1989 & $4.30 \%$ & $-0.32 \%$ & 1.34 & 0.25 & $-4.30 \%$ & $0.32 \%$ & 1.34 & 0.25 \\
\hline 24 & Mauritania & First & 1995 & $-6.13 \%$ & $-24.14 \%$ & 0.40 & 0.12 & $0.98 \%$ & $0.85 \%$ & 0.26 & 0.41 \\
\hline 25 & Dominican Republic & First & 1992 & $0.91 \%$ & $-4.72 \%$ & 0.44 & 0.26 & $-0.91 \%$ & $4.72 \%$ & 0.44 & 0.26 \\
\hline 26 & Botswana & First & 1979 & $-4.90 \%$ & $-7.33 \%$ & 0.51 & 0.34 & $4.90 \%$ & $7.33 \%$ & 0.51 & 0.34 \\
\hline 27 & South Africa & First & 1991 & $-15.85 \%$ & $-51.97 \%$ & 0.22 & 0.09 & $15.85 \%$ & $51.97 \%$ & 0.22 & 0.09 \\
\hline
\end{tabular}

Notes: The Table summarizes the key SCM results at the country level by excluding from the donor pool those countries that share a national border with the treated unit in order to account for the possible violation of the SUTVA. The SCM experiments presented in bold are those where border countries were included in the synthetic control in the previous (baseline) experiments. The right hand side of the table presents the SCM results for these countries when excluding from the donor pool the border ones. The magnitude of the "average treatment effect" of trade liberalization on the U5MR is measured as the \% deviation of the treated country in comparison to the (counterfactual) synthetic control. The detailed results for the SCM experiment in bold are not shown to save space, but are available upon request. Percentage differences between the average treatment effect in treated and untreated countries are obtained by considering normalized values of child mortality (i.e. child mortality in treated countries equal to 1 at time $T_{0}$ ). 
Table A3: Average HIV Prevalence (\% of population age 15-49) in the Post-treatment Period in Countries in Group 1 and 2

\begin{tabular}{|c|c|c|c|c|c|c|c|c|}
\hline \multicolumn{3}{|c|}{ Significant Reduction } & \multicolumn{3}{|c|}{ Not Significant } & \multicolumn{3}{|c|}{ Significant Increase } \\
\hline Country & $\begin{array}{l}\text { HIV } \\
(\%)\end{array}$ & Group & Country & $\begin{array}{l}\text { HIV } \\
(\%)\end{array}$ & Group & Country & $\begin{array}{l}\text { HIV } \\
(\%)\end{array}$ & Group \\
\hline $\begin{array}{l}\text { Burundi } \\
\text { Guatemala } \\
\text { Nicaragua } \\
\text { Peru } \\
\text { El Salvador } \\
\text { Tanzania }\end{array}$ & $\begin{array}{l}2,6 \\
0,1 \\
0,4 \\
0,6 \\
0,3 \\
7,7\end{array}$ & $\begin{array}{l}1 \\
1 \\
1 \\
1 \\
1 \\
1\end{array}$ & $\begin{array}{l}\text { Ivory Coast } \\
\text { Dominic. Rep. } \\
\text { Ghana } \\
\text { Honduras } \\
\text { Morocco } \\
\text { Mauritania } \\
\text { Tunisia } \\
\text { Benin } \\
\text { Burkina Faso } \\
\text { Cape Verde } \\
\text { Ethiopia } \\
\text { Guinea Biss. } \\
\text { Madagascar } \\
\text { Mexico } \\
\text { Paraguay }\end{array}$ & $\begin{array}{l}5,3 \\
1,7 \\
1,7 \\
1,3 \\
0,1 \\
0,8 \\
0,1 \\
\\
\\
1,0 \\
1,8 \\
0,7 \\
2,8 \\
0,7 \\
0,5 \\
0,7 \\
0,1\end{array}$ & $\begin{array}{l}1 \\
1 \\
1 \\
1 \\
1 \\
1 \\
1 \\
\\
2 \\
2 \\
2 \\
2 \\
2 \\
2 \\
2 \\
2\end{array}$ & South Africa & 9,7 & 1 \\
\hline
\end{tabular}

Notes: Table reports the level of HIV prevalence in countries belonging to Group $1+2$, considering their average effect and significant level. See Text. 